\title{
The Foreign Investor Bias and its Linguistic Origins
}

\author{
by \\ Russell Lundholm \\ University of British Columbia Sauder School of Business \\ Russell.Lundholm@sauder.ubc.ca \\ 778-877-0621 \\ Nafis Rahman \\ University of British Columbia Sauder School of Business \\ Nafis.Rahman@sauder.ubc.ca \\ Rafael Rogo \\ University of British Columbia Sauder School of Business \\ Rafael.Rogo@sauder.ubc.ca
}

March 2016

\begin{abstract}
We study how misaligned language between the investor and the firm contributes to the foreign investor bias. In particular, we document a significant US institutional investor bias against firms located in Quebec relative to firms located in the Rest of Canada (ROC). The differential bias is surprising given that Quebec and the ROC share the same country, federal law, stock exchange, accounting standards, and regulatory filings are prepared in both English and French; and given that US institutional investors are sophisticated investors at close geographic proximity to both Quebec and the ROC. We also contrast the bias of Quebec firms with different levels of French versus English online presence, and we contrast the bias of institutional investors located in the UK versus France, to bolster our conclusion that incongruent languages are a major source of bias.
\end{abstract}

JEL Classifications: F3, G15. Keywords: home bias, language, Quebec

We would like to thank Mary Barth, Stephannie Larocque, and the workshop participants at the University of Calgary, the University of Miami, Simon Fraser University, and at the Notre Dame Research Conference and the Brazilian Business Review conference, for their helpful comments. 


\section{Introduction}

It is well documented that international investors have a bias that causes them to underweight foreign stocks in their portfolio, and at a rate that is increasing in the distance from their domestic country. Because financial assets are weightless, the distance between the foreign investor and the domestic firm must be a proxy for some other, more fundamental, source of bias. Country differences in accounting rules, investor protection laws, cultural norms, and language have been shown to predict the degree of bias, with varying degrees of success. Unfortunately, different countries present packages of these attributes, so that comparing the foreign investor bias across countries necessarily varies many of these factors at the same time.

In this context, foreign investment in Canada presents an interesting case. Since the Constitution Act of 1876, Canada has had two official languages, French and English, with French spoken primarily in Quebec, and English spoken primarily in the other nine provinces. However, the accounting rules are the same across the country, regulatory filings and accounting disclosures are prepared in both languages, and the geographic distance from most foreign investors is approximately the same. Thus, while some differences remain between firms located in Quebec and firms located in the Rest of Canada (ROC), many of the differences that arise when comparing firms in different countries do not exist.

In this study we find a surprising result: despite an almost identical information environment and very close geographic proximity, and after controlling for a host of firmlevel characteristics, we find that US institutional investors have a significantly larger bias against firms located in Quebec than firms located in the ROC. In addition, by contrasting the bias within Quebec firms based on their English versus French online presence, and by 
contrasting the bias of UK versus French institutional investors, we show that misaligned language between the investor and the firm is a significant cause of the differential bias between Quebec and the ROC. Although other studies have found that misaligned language may contribute to the foreign investor bias, our study does so with considerably fewer alternative explanations, and shows that even sophisticated institutional investors living in close proximity to the firms in a foreign country are greatly deterred by a foreign language. ${ }^{1}$

Quebec's place among Canadian provinces is unique. France colonized the region following the explorations of Jacque Cartier. France later ceded the region to the British in the Treaty of Paris in 1763; shortly thereafter the British established Quebec. From then to present day, approximately 80 percent of Quebec inhabitants speak French as their first language (Statistics Canada 2011). This contrasts to roughly two percent Francophones elsewhere in Canada. Coincident with its unique use of the French language, Quebec evolved with many unique business characteristics and cultural differences from the ROC. Finally, Quebec is an economically important part of Canada, representing 20 percent of Canadian GDP in 2012 (Statistics Canada 2012). The question arises, how do foreign investors view firms located in Quebec relative to firms located in the ROC? And, to the extent that we discover a bias against Quebec firms, can we attribute some of it to misaligned language between the foreign investor and the Quebec firm?

Our first contrast treats all the unique features of Quebec as a bundle and measures the US institutional investor bias against Quebec relative to the bias against the ROC. Using

\footnotetext{
${ }^{1}$ We acknowledge that a region's language is confounded with other aspects of its culture, and that it would be impossible to disentangle language from culture. We will sometimes use the phrase 'language/culture' to remind the reader of this.
} 
a variety of specifications, we find compelling evidence of an incremental bias against Quebec. We find that US investors hold significantly smaller percentages of Quebec firms than firms in the ROC and place significantly less weight on Quebec firms than ROC firms in their Canadian portfolio. These results hold after controlling for a battery of firm-specific characteristics, including whether the firm is cross-listed in the US, whether it has a US segment, whether it is incorporated under provincial or federal law, its size, past performance, dividend yield, and number of analysts. The magnitude of the bias against Quebec relative to the ROC is roughly comparable to the difference between being crosslisted in the US or not. In one specification, US ownership of Quebec firms is 35.9 percent lower than ownership of ROC firms, and the relative portfolio weight on Quebec firms is roughly half the weight put on ROC firms in the Canadian portfolio.

Our next two contrasts are aimed at identifying the effect of language/culture on the size of the bias against Quebec firms. While it is impossible to isolate and quantify the contribution of each unique feature of Quebec firms that might contribute to a foreign investor bias, we control for a number of previously documented sources of bias that differ between firms within Quebec. For our first language contrast we vary attributes of the firm by creating a cross-sectional measure of each Quebec firm's French presence on the Internet. Specifically, we measure the firm's 'Frenchness' by counting the relative number of French versus English language documents resulting from a Google search of the company name. We find that a 10 percent increase in the firm's Frenchness is associated with a 4.9 percent reduction in US ownership and a 79 percent reduction on the firm's relative portfolio weight in the US investor's Canadian portfolio.

Our second language contrast varies the native language of the foreign investor. By contrasting the bias from British institutional investors with the bias from French 
institutional investors, we change the alignment of language between the firm and investor but keep many other sources of bias constant. After controlling for a number of firm characteristics, we find that the difference between the British bias and the French bias is much larger for Quebec firms than for ROC firms. In one specification the British investors favour ROC firms over Quebec firms while French investors favour Quebec firms over ROC firms.

\section{Literature Review and Hypothesis Development}

French and Poterba (1991) document that, while US firms represent 49 percent of the equity capital in the largest 6 markets, US investors allocate 91 percent of their wealth to US firms. The tilt of investment portfolios away from global diversification in favour of domestic stocks, a phenomenon labeled as the 'home bias,' has been shown in many different countries (Tesar and Werner 1995). With respect to US investment in Canada, Andrade and Chhaochharia (2010) show that in 2001-2006 US investors allocated one percent of their portfolio to Canadian equity, on average, while Canadian equity averaged three percent of the world portfolio over the same period. The most robust empirical predictor of the degree of bias is simply the geodesic distance between the investor's country and the firm's country (Portes, Rey and Oh 2001; Portes and Rey 2005). This result, known as the 'gravity model,' is generally thought to be a proxy for more fundamental determinants of the bias, as financial assets do not have 'weight.' The search for other notions of distance that capture the true obstacles to foreign investment has spawned a rich literature in accounting, economics, and finance.

We ask two broad questions: 1) do US investors exhibit a bias against Quebec firms that differs from the bias against ROC firms, and 2) does part of any incremental bias 
against Quebec have a basis in language and its associated cultural attributes? Accordingly, we sort the related literature into 1) differences between Quebec and the ROC that may contribute to an investor bias, but are relatively constant for firms within Quebec, 2) firm attributes or investor attributes that may cause the bias to differ between firms within Quebec or across investor locations. We also briefly discuss forces that have been found in previous literature to contribute to an investor bias but are notably absent in our study, and forces that influence institutional holdings quite apart from a foreign investor bias.

\subsection{SOURCES OF BIAS THAT DIFFER BETWEEN QUEBEC AND REST OF CANADA}

While contrasting Quebec with the ROC holds many country features constant, there are still reasons to believe US investors will have an additional bias against Quebec firms. The bundle of differences between Quebec and the ROC collectively form the explanation for any differences we may find between the regions.

\subsubsection{Language}

The most obvious difference between Quebec and the ROC is the relative use of French; 80 percent of Quebec residents speak French as their first language, as opposed to only 2 percent in the ROC (Statistics Canada 2011). Language can proxy for economic impediments, such as the cost of gathering information, and it can also proxy for psychological impediments - a firm in a region that speaks a different language feels less familiar to a foreign investor than a firm in a region that speaks the investor's domestic language. ${ }^{2}$ Consistent with this, in a study of 97 Finnish firms and local Finnish investors,

\footnotetext{
2 Cao, Han, Hirshleifer and Zhang (2011) present a model where the uncertainty created by unfamiliar assets induces pessimism in investors, resulting in less demand. Due to differences in language and culture, it is
} 
Grinblatt and Keloharju (2001) find the Finnish-speaking household investors favour firms that publish their annual reports only in Finnish, while Swedish-speaking household investors prefer firms that publish their annual reports only in Swedish (Finland has two official languages); in contrast to our results, they find no language affect for institutional investors. In global studies, there is mixed evidence that sharing a common language impacts the flow of cross-border investment. Aviat and Coeurdacier (2007) find no evidence that a common language matters in cross-border trade, Portes and Rey (2005) and Daude and Fratzcher (2006) find mixed results for equity investments, while Lane and Milesi-Ferretti (2008), Beugelsdijk and Frijns (2010), and Aggarwal, Kearney and Lucey (2012) find that sharing a common language improves cross-border equity investment. ${ }^{3}$ An interesting feature of the information environment in Canada in this regard is that all Quebec firms file regulatory reports in SEDAR in both English and French. While these filings do not constitute the complete information environment, the fact that annual and interim financial statements, MD\&A discussions, and material change reports are all available in English certainly lowers the information processing costs, the information advantage of local investors, and the psychological distance of Quebec firms relative to firms located in the ROC. Whether this 'levels the playing field' for a US Anglophone investor is an empirical question.

easy to imagine that Quebec companies feel less familiar to US institutional investors than companies located in the ROC, and the model would therefore predict lower investment in Quebec companies. In their model, as in our results, the bias can be so extreme that a status quo of zero holdings of Quebec companies is a possible equilibrium outcome.

${ }^{3}$ While the results of these global studies are informative, we note that, unlike our study, global studies vary many things besides language when they compare across countries. In addition, these studies aggregate investment at the country level, while we collect data at the firm level. This allows us to control for variation in firm characteristics that have been shown to influence institutional investment, and that gets lost in country aggregation. 


\subsubsection{Culture}

Beyond the difference in language, there are many other cultural differences between Quebec and the ROC that may influence a US investor's perception of the firm. Two recent global studies of cross-border investment, Beugelsdijk and Frijns (2010) and Aggarwal et al. (2012), find that cultural distance is a significant deterrent to foreign investment in developed countries, even after controlling for geographic distance and the effect of sharing a common language. First introduced by Kogut and Singh (1988), the cultural distance measure is derived from Hofstede's four cultural dimensions, and is often used in international business research (e.g., Loree and Guisinger 1995, Barkema and Vermeulen 1997, Brouthers and Brouthers 2001). ${ }^{4}$ For each country, the Hofstede Centre gives a score ranging from 1 to 120 on the dimensions of power distance, individualism, uncertainty avoidance, and masculinity. The cultural difference between any two countries is given as the Euclidean distance between the two countries (i.e. the square root of the sum of the squared differences). Along with country scores, the Hofstede Centre gives scores for Quebec separately. The four scores for Canada are $(39,80,52,48)$, as compared to $(54,73,45,60)$ for Quebec, and $(40,91,62,46)$ for the US. Thus, the cultural distance between Canada and the US is 15 and the distance between Quebec and the US is 32 . As a point of reference, the distance between England and the US is 34. Aggarwal et al. (2012) find that the impact of cultural distance is positively related to geographic distance and so the close proximity of Canada and the US may render the cultural distinction between Quebec and the ROC irrelevant. Further, they find that greater levels of power distance and

\footnotetext{
4 The cultural measures given in Hofstede, Hofstede and Minkov's Culture and Organizations (1997) are arguably the most common proxies for a country's culture, having been cited more than 21,000 times according to Google Scholar.
} 
masculinity in the foreign investment destination country are positively associated with more cross-border investment, which would favour Quebec over the ROC because Quebec scores higher on these two dimensions. It is therefore an empirical question whether the differences in relatively "close" cultures is sufficient to generate an incremental investor bias against Quebec or if the aspects of Quebec's culture that are more masculine with more unequally distributed power actually attracts US investment.

\subsubsection{Political Risk}

The Parti Quebecois (PQ) is a separatist political party in Quebec that advocates national sovereignty for Quebec. Such an outcome could raise significant concerns for US investors who might fear a disrupted business environment, changes in the relative power of labour markets, severe limits on mergers with firms from outside Quebec, and the possible expropriation of assets. The PQ first took power in 1976, with a failed referendum for secession in 1980. They were defeated in 1985 but returned to power in 1994 with another referendum for secession in 1995. The referendum failed, but by a margin of less than one percent. The PQ was defeated in 2003, and fell to third place in the 2007 election. They won a minority government in 2012, but after calling an election in 2014 , they lost power to the liberal party, and won only 25 percent of the popular vote, the worst result since 1970. Although the PQ's political power ebbs and flows, their continued existence as a major party in Quebec poses a political risk to foreign investors.

Evidence that investors price the political risk associated with Quebec's intermittent sovereignty movement can be found in Beaulieu, Cosset and Essaddam (2006) who study stock price movements of Quebec firms around the 1995 referendum. Polls prior to the vote could not reliably predict the outcome, making stock returns prior to the vote 
sensitive to the uncertainty of the outcome, and stock returns surrounding the vote sensitive to the resolution of that uncertainty. The authors find that in the week prior to the vote, the stock returns of Quebec firms were significantly negative, and then turned significantly positive in response to the NO vote on the referendum. In addition, Tirtiroglu, Bhabra and Lel (2004) find positive stock price reactions to announcements that a firm is moving its headquarters, plants, or divisions away from Quebec. Finally, Graham, Morrill and Morrill (2005) find that firms headquartered in Quebec tend to have higher book-toprice ratios than firms headquartered elsewhere in Canada. Equity prices clearly behave as if firms in Quebec come with political risk to foreign investors. However, prior research does not study how Quebec's political risk, and its associated price discount, influence US investor holdings in Quebec versus the ROC.

\subsubsection{Investor Protection}

It has been argued that the foreign investor bias is partly driven by differences in the legal protection afforded foreign investors. La Porta, Silanes, Shleifer and Vishny (1997) argue that common law countries provide greater investor protection than civil law countries, both in terms of specific laws and because of better enforcement. Because Quebec is a civil law jurisdiction, while the rest of the Canadian provinces and the federal government are common law jurisdictions, this might support a foreign investor bias against Quebec. But perhaps not surprisingly, the La Porta measures of investor protection, and the conclusions drawn from them, have been disputed by legal scholars. Spamann (2010) finds that when the components of the La Porta binary coding system are augmented to a richer coding system, there is no longer a difference between common law and civil law countries in terms of investor protection. Further, Puri (2009) writes that the 
La Porta et al. (1997) arguments are too broad-brushed to apply simplistically to Quebec versus the ROC. The author notes that the organization of the Canadian Securities

Administrators in 2003 has helped to harmonize rules across the provinces, and the creation of the National Instruments has aided in setting out common regulations. The author summarizes by stating

"This discussion reveals that while Quebec operates a corporate law framework within its civil law system that on the surface provides legal rules that do not offer as much protection as the federal corporate law statute (or other provincial law statues), the Quebec courts have stepped in to judicially craft remedies for shareholders. That being said, these QCA remedies are currently more difficult to access or achieve recourse under than those in the federal statutory regime." (Puri 2009 p. 1671).

We simply note that Quebec operates under a different legal system than the ROC and this may have economic implications for foreign investors. As discussed in the next section, we investigate one component of investor protection that varies across firms within Quebec by examining whether there is a difference between firms who incorporate under Quebec provincial law versus those who incorporate under federal law. ${ }^{5}$

\subsubsection{Forces that are the same between Quebec and the Rest of Canada}

Some previously documented drivers of the foreign investor bias are notably absent from our study. The accounting rules are the same across Canada, eliminating one prominent and frequently studied cause of the bias. ${ }^{6}$ And, as discussed previously, all

\footnotetext{
${ }^{5}$ An investor protection issue that applies across Canada is that each province has its own security regulatory body. However, under the passport system most provinces agree to respect each other's registration decisions (Canadian Securities Administrators 2014). Ontario does not officially participate in the passport system, lobbying instead for a national regulatory system. The other provinces accept Ontario's decisions while Ontario reserves the right to makes its own decisions.

${ }^{6}$ Bradshaw, Bushee and Miller (2004) find that foreign firms with greater degrees of US GAAP conformity have greater levels of US institutional investment. Interestingly, the authors exclude Canada from the sample, arguing that the accounting rules are so close to US standards that there is no meaningful variation. Similarly, Covrig, Defond and Hung (2007) find that foreign ownership of a firm is higher for IAS adopters. And in a
} 
significant regulatory disclosures - annual reports, MD\&A, material changes - are produced in English and filed electronically. In addition, even if geographic distance from the US is a relevant determinant of the foreign investor bias, Quebec and the ROC are approximately the same distance from the US. Thus, our study holds constant many factors that have been shown to have large influences on the foreign investor bias, and therefore narrows the range of explanations for any bias against Quebec that we might observe. ${ }^{7}$

\subsubsection{Hypothesis 1}

Collectively, the differences between Quebec and the ROC in language, culture, political risk, and investor protection may give rise to a US investor bias against Quebec that is over and above a bias against the ROC. Or it may be that the differences between these forces are sufficiently minor that, when combined with the uniformity of accounting rules and the small and roughly equal geographic distance from the US, there is no measurable difference on US investor behaviour. Therefore, we empirically assess the following alternative hypothesis.

H1: The US institutional investor bias against Quebec firms is greater than the bias against firms in the Rest of Canada.

changes design, Wahid and Yu (2012) find that international mutual fund ownership increases following adoption of IFRS.

7 Transaction costs are virtually the same for investments in Quebec versus the ROC. However, transaction costs have generally been dismissed as a viable cause for the foreign investor bias. Rowland (1999) shows that international portfolios turn over faster than similar domestic portfolios, suggesting that transaction costs are unlikely to be significantly higher for international investments. 


\subsection{DOES PART OF THE INVESTOR BIAS AGAINST QUEBEC HAVE A BASIS IN LANGUAGE?}

The collective differences between Quebec and the Rest of Canada, to the extent that they exert a differential impact on US investor holdings, are mutually confounded. To gain some insight into the relative contribution of different sources of bias, in this section we develop hypotheses about forces that will vary within the Quebec firm sample, and forces that differ across different foreign investor populations. Our emphasis is on investigating how differences in language/culture contribute to the differential foreign investor bias against Quebec firms. We develop two hypotheses in this regard.

\subsubsection{Frenchness}

Prior research has treated language differences between the investor location and the firm location as a country-level dichotomous variable - either the investor's country shares the same language as the firm's country or it does not (e.g. Beugelsdijk and Frijns 2010 and Aggarwal et al. 2012, Lundholm et al. 2014). Such an approach cannot disentangle language from other regional influences. To sidestep this problem, we create a measure of "Frenchness" for each Quebec firm. Within Quebec, firms can have very different levels of English versus French personas. Some firms may translate every voluntary disclosure, do interviews in both languages, staff investor relations departments with both Anglophones and Francophones, while other firms may do little to help the nonFrancophone investor. We create a comprehensive proxy for this tendency by measuring the relative number of firm-related documents on the web published in French or English. We describe this measure, labeled 'Frenchness,' in detail in the next section, but for now it is interesting to note that it ranges from 0 to 67 percent of online documents, suggesting 
that there is considerable variation in the mix of language that a foreign investor might

find. ${ }^{8}$ If the foreign investor bias against Quebec firms varies with the degree of Frenchness, this is an indicator that language, along with the cultural aspects that it proxies for, is a critical part of the reluctance of US investors to own Quebec stocks.

\subsubsection{Type of Incorporation}

Firms within Quebec can also vary in ways that influence the degree of investor protection. Boubraki, Bozec, Laurin and Rousseau (2011) find that many Quebec firms incorporate under federal law rather than under provincial law, arguing that federal law is more protective of investor rights. ${ }^{9}$ Of our Quebec firms, 36 percent are incorporated under Quebec provincial law, providing an interesting contrast in investor protection within Quebec.

\subsubsection{Cross-listing}

A Quebec firm can also enhance foreign investor protection, and attract US investors, by cross-listing its stock on a US exchange. In a global study Ahearne, Griever and Warnock (2004) find that US investors hold more equity in countries who have a greater fraction of their firms cross-listed in the US, arguing that this lowers the information asymmetry. In a valuation study, King and Segal (2009) find that Tobin's Q increases for a

\footnotetext{
${ }^{8}$ We observe variation in the mix of French and English despite Quebec's Bill 101, which requires all businesses with more than 50 employees to use French in signage, product labels, manuals, software, business communications, along with every employee's right to conduct his or her work in French. However, a second language is allowed in addition to the mandatory French as long as the French version is the most prominent.

${ }^{9}$ In 2011 Quebec replaced the Quebec Companies Act with Quebec Business Corporations Act. The change was designed, in part, to provide better protection to shareholders under provincial law. As this event occurred at the very end of our sample period, we do not attempt to measure its impact.
} 
Canadian firm that cross-lists on a US exchange, but only if the firm's US investor base also increases. The authors do not distinguish between Quebec firms and firms from the ROC. Further, they attribute their results to an increase in investor recognition (Merton 1987) rather than heightened investor protection. Roughly 30 percent of the Quebec firms in our sample have cross-listed shares in the US, thus providing another within-Quebec contrast on this determinant of the US investor bias.

\subsubsection{Differential Exposure to Political Risk}

Beyond the different types of incorporation, Quebec firms can have different exposures to the political risk that Quebec presents. Beaulieu et al. (2006) find that the stock price changes around the 1995 Quebec succession referendum were more pronounced for purely domestic Quebec firms than for multinational firms with headquarters in Quebec. They argue that firms whose value is based largely on growth options have less exposure to Quebec's political risk because they can move those growth options to other locations at relatively low cost. Similarly, they argue that a Quebec firm that has foreign segments has less exposure to political risk inside Quebec. And, from a US investor prospective, the political risk may be lowest if the foreign segment is in the United States. Building on the variation in political risk that different Quebec firms pose, Graham et al. (2012) use the number of employees, the amount of revenue, and the value of assets located in and out of Quebec, as reported in an annual survey by Les Affairs, to measure the firm's political risk. They find lower valuation multiples on the firm's book value and earnings as the amount of assets located in Quebec increases. ${ }^{10}$

${ }^{10}$ The authors of Graham et al. (2005) graciously provided their hand-collected data on the number of employees in and out of Quebec. This variable was insignificant in our tests, probably because intersecting 


\subsubsection{Hypothesis 2}

Our treatment variable of interest is the firm's degree of "Frenchness" on the Internet. Based on prior research, we also control for differences in the type of incorporation, cross-listing in the US, and exposure to political risk (which we proxy for with the existence of a US segment). We note that all of these cross-sectional differences between firms in Quebec are firm choices and therefore may be the product of even more fundamental influences. Also, because these attributes are relatively stable over time, we cannot attribute causation. In particular, it may be the case that US investors are repelled by firms with high Frenchness, or it may be the case that firms choose a low level of Frenchness because they have many US investors, or it may be the case that both variables are jointly determined over many years.

H2: The US investor bias against Quebec firms increases with a firm's "Frenchness."

\subsubsection{Hypothesis 3}

In global studies of mutual fund holdings, Chan, Corvig and Ng (2005), Beugelsdijk and Frijns (2010), and Aggarwal et al. (2012) find that sharing a common language reduces the investor bias against foreign countries. Note that these results measure cross-border investments at the country level. They do not take into account firm-level attributes, such as the firm's location within the country, the firm choices outlined in hypothesis two, or the host of other firm attributes that have been shown to influence institutional investment (as

this data with ours greatly reduced the sample size. More importantly, none of our results where significantly affected. 
discussed next). If misaligned language contributes to a foreign investor bias, we would expect the bias against Quebec to be stronger for investors residing in an Anglophone country than for investors residing in a Francophone country. We choose France and the UK as the investor locations for this contrast because they each have a reasonable number of institutional investors and they are approximately the same geodesic distance from Canada. In addition, by choosing two countries that are significantly further from Canada than the US we reduce the potential level of familiarity that proximity alone may have provided the US investor. Finally, note that if any of the non-language features of Quebec (political risk, investor protection, etc.) are the root cause of the bias then this is the same for French and British investors, and we would find no difference.

H3: The bias against Quebec firms, relative to the bias against firms in the Rest of Canada, is greater for British institutional investors than it is for French institutional investors.

\subsection{DETERMINANTS OF INSTITUTIONAL HOLDINGS UNRELATED TO HOME BIAS}

Kang and Stulz (1997) and Bradshaw et al. (2004) identify a number of firm-specific factors that attract institutional investors. And, in a study of Swedish firms' foreign ownership, Dahlquist and Robertsson (2001) find that many of the firm attributes that are attractive to institutional investors in their domestic portfolios (e.g. size, low dividend payout) are also present in the Swedish firms that are targeted by foreign investors, particularly US investors. They argue that some previous evidence regarding a foreign investor home bias is actually just an institutional investor bias in favour of certain firmspecific attributes found in foreign firms. For this reason, in addition to the variables discussed above, we control for the firm-specific factors found in these studies. We also 
include industry fixed effects to account for the different mix of industries in Quebec versus the ROC, and we include the provincial marginal tax rate as a proxy for business costs that vary across provinces. And, to satisfy the exclusion restriction in the two-stage models that follow, we use an indicator for whether the firm is part of the S\&PTSX index when modeling the decision for institutional ownership to be zero or positive.

\section{Research Design}

\subsection{THE DEPENDENT VARIABLES}

There are two common ways to measure the degree of foreign investor bias against a domestic stock: 1) the percent of shares held by specific foreign investors (either in the US, the UK or France), and 2) the portfolio weight of the firm in the foreign investor's Canadian holdings relative to the weight of the firm in the Canadian market. The benchmark for both ratios is given by the international CAPM; in this model every investor should hold the market-value-weighted world portfolio. In this case the percent of shares held by specific foreign investors should be constant across all firms in Canada, regardless of whether they are in Quebec or ROC. The percent of shares held is used by Bradshaw et al. (2004) to study how accounting differences impact the home bias and by DeFond, Hu and Li (2011) to study the impact of mandatory IFRS adoption in the European Union. It is the most commonly used measure in the institutional ownership literature (see Bushee 1998 and 2001). Similarly, under the international CAPM the relative portfolio weight should be one for all securities, regardless of their location within Canada. The relative portfolio weight is used in Dahlquist and Robertsson (2001) to study how firm characteristics influence foreign investor ownership in Sweden. It is a firm-level version of the countrylevel variable used in most economics studies of aggregate cross-border investment, 
including Dahlquist, Pinkowitz, Stulz and Williamson (2003), Chan et al. (2005), and Beugelsdijk and Frijns (2010).

Note that a general home bias against Canada will not change the relative value between Quebec and ROC for either measure; it depresses the percent of shares held equally across all Canadian firms and it has no effect on the relative portfolio weight because the allocated share of wealth is relative to the investor's holdings in Canada. The first measure is from a firm perspective - who owns the firm's shares. The second measure is from the investor's perspective - how do they allocate their wealth between Canadian firms? In both cases, the unit of observation is the firm-year because we only consider one group of foreign investors at a time.

For a given Canadian firm and year, the percent of shares held, $P C T_{-} U S$, is defined as the number of shares held by U.S. institutional investors, measured as of the institutional report date closest to the fiscal year end, divided by the float-adjusted shares. Floatadjusted shares are shares outstanding less the number of shares held by 'control blocks' at the end of the fiscal year (COMPUSTAT item CSFSM). Control blocks are assumed to be held partly for strategic and not solely for investment purposes; consequently, they are not generally available for sale to foreign investors. ${ }^{11}$ Dahlquist et al. (2003) show that investor bias estimates based on the total shares outstanding severely distort the result toward a biased measure of investment even if no bias is actually present, and Attig (2007) presents evidence that closely held shares are particularly prevalent in Quebec. We use float-

\footnotetext{
${ }^{11} \mathrm{~S} \& \mathrm{P}$ computes control blocks as those shares that are a) held by another corporation; b) shares held by government entities; c) shares held by current and former officers, directors, founders or family trusts thereof; and d) shares held by trusts, pension funds, and employee stock ownership programs controlled by the company. If the sum of such shares exceeds 10 percent of shares outstanding, then this sum is subtracted from the shares outstanding to arrive at the float-adjusted number of shares. For a more detailed description, see Standard and Poor's (2011).
} 
adjusted shares rather than total shares outstanding to avoid biasing our 'bias' estimate, but as a practical matter our results are virtually the same throughout the paper if we use total shares outstanding as the denominator.

The relative portfolio weight, $R P W_{-} U S$, is defined as the weight of the firm in US investors' Canadian portfolio compared to its weight in Canadian equity market. Let $M V_{j}^{U S}$ denote the total dollar amount invested by the US institutional investors in firm $\mathrm{j}$. If there are $\mathrm{N}$ firms in the Canadian equity market, then firm j's weight in the US investors' Canadian portfolio is $W_{j}^{U S}=M V_{j}^{U S} / \sum_{j=1}^{N} M V_{j}^{U S}$. Similarly, let $M V_{j}$ denote the market value

of firm j. Then firm j's weight in the Canadian market portfolio is $W_{j}^{M}=M V_{j} / \sum_{j=1}^{N} M V_{j}$. The relative portfolio weight of firm $\mathrm{j}$ for US investors is thus defined as: $R P W_{-} U S=$ $W_{j}^{U S} / W_{j}^{M}$. As with the $P C T_{-} U S$, all calculations use the float-adjusted number of shares. In the second part of our analysis we contrast British and French investments in Canada - for these measures we define PCT_UK, PCT_FRANCE, RPW_UK, and RPW_FRANCE exactly as described above, but substitute in the relevant country's institutional holdings data.

\subsection{THE INDEPENDENT VARIABLES}

For the first and third hypothesis our treatment variable of interest is $Q C$, an indicator variable that takes the value of one for firms headquartered in Quebec and the value zero for firms headquartered in the ROC (as given by COMPUSTAT). For the second hypothesis the treatment variable is FRENCHNESS, which measures a firm's online presence in French versus English (as described later).

As discussed in the last section, we use a common set of control variables in all our models to capture firm characteristics that previous literature has found to influence 
institutional investment quite apart from any foreign investor bias (precise definitions are given in Table 1). Following Bradshaw et al. (2004), we control for firm SIZE, firm AGE, whether the firm reports US segment sales (USSEGMENT), whether the firm is cross-listed on a US exchange (USCROSS), the number of analysts providing forecasts (NANLST), the fiscal year's sales growth $(G R O W T H)$, the return on beginning equity ( $R O E)$, the debt-toasset ratio ( $L E V E R A G E)$, the earnings-to-price ratio $(E P)$, the book-to-price ratio $(B P)$, the dividend yield $(D P)$, the raw stock return over the fiscal year (RRET), and whether the firm uses a Big 4 auditor (BIG4). All income statement variables are measured over the fiscal year and all balance sheet variables are measured as of the end of the fiscal year. In addition, because Quebec may represent a different mix of industries than the rest of Canada, and institutional investors may have industry preferences, all our tests include industry fixed effects.

As discussed in the literature review, USCROSS and USSEGMENT have been used in prior valuation studies of Quebec, and so we are careful to report their effects in all our tables. In addition, we include an indicator variable $P R O V_{-} I N C P$ equal to one if the firm is incorporated under its provincial law, and equal to zero if it is incorporated under the Canadian Business Corporation Act or other federal regulation; this variable has also been used in previous studies of Quebec. These three variables are particularly important for the within-Quebec analysis (which tests hypothesis two) in order to isolate the effect of FRENCHNESS. Finally, we include the provincial marginal tax rate $\left(P R O V_{-} T A X\right)$ as a proxy for how friendly the province is to business, and in the models that require an exclusion restriction, we include an indicator variable equal to one if the firm is part of the S\&PTSX index, and equal to zero otherwise. 


\subsection{EMPIRICAL MODELS}

Our first dependent variable, $P C T_{-} U S$, is a proportion, so it lies on the unit interval, and it has a discontinuously large mass of observations at zero. In addition, the variables and relative weights that cause a firm to have zero US institutional ownership might be different from the variables and weights that determine how much US ownership a firm has, given that it is greater than zero. Consequently, a simple OLS regression is not appropriate because, with OLS a) the predicted value from a linear relationship can extend infinitely beyond the unit interval, and b) the determinants that give rise to a prediction of zero can only be slightly different from the determinants that give rise to a small positive prediction. To better align our model with our data, we borrow a model that has been used to estimate the proportion of debt in a firm's capital structure.12 Called the zero-inflated beta model, it incorporates the features above, and its application to the capital structure problem is found in Cook et al. (2008).13 Because this model is not commonly used, we provide a brief description here, and give the detailed model in Appendix 1. We also supplement our analysis of $P C T_{-} U S$ with traditional OLS regressions on the full sample and on the sample restricted to non-zero holdings.

The zero-inflated beta model produces two simultaneously-estimated results; the coefficients for a logit model on an indicator for whether PCT_US is zero or greater than zero and, for the observations where PCT_US is greater than zero, coefficients for a model of the level of PCT_US, where the percent is estimated as the mean parameter in a beta

\footnotetext{
12 Note that the capital structure problem also models a proportion, has a large mass of observations at zero, and there is reason to believe that what causes a firm to have zero leverage might be different from what determines how levered a firm is once the value is greater than zero.

13 There is a rich statistics literature on the issue of proportions with a mass at zero. See Kieschnick and McCullough (2003), and Ferrari and Cribari-Neto (2004) for solutions to the distributional issues and Heckman (1979) for a discussion of the selection issue that distinguishes the zero observations from the positive ones.
} 
distribution (noting that the beta distribution is on the unit interval). To parallel the Heckman model that follows, we label the logit model as the 'selection model' and the beta model as the 'final model.' The estimation is performed using the ZOIB module in STATA, which allows for fixed effects and clustered standard errors. Finally, for some specifications we limit the data to the observations with positive $P C T_{-} U S$ and, for these models, we estimate a simple beta model, which retains the property of being constrained on the $(0,1)$ interval but without the selection portion of the zero-inflated beta model.

Our second dependent variable, $R P W_{-} U S$, has the same selection issue as $P C T_{-} U S$ in that it also has a mass of observations at zero that are unlikely to have arrived there randomly, but it isn't constrained to the unit interval. Therefore, for this dependent variable we estimate a Heckman two-stage model, where the first stage is a probit model on an indicator for whether $R P W_{-} U S$ is zero or greater than zero and the second stage is an OLS regression that includes the inverse Mills ratio from the first stage. We also supplement our analysis of this variable with traditional OLS regressions.

Both the zero-inflated beta model and the two-stage Heckman model are much improved if an exclusion restriction is included in the first-stage selection model; this lowers the potential correlation between the errors in the selection model and the errors in the final model. We use an indicator for inclusion in the Standard and Poor's TSX index as our exclusion variable (S\&PTSX), reasoning that it will have a much greater impact on whether or not US institutional investors have non-zero holdings of the firm than on the level of investment, given that investment is positive.

To summarize, both the zero-inflated beta model and the two-stage Heckman model consist of a selection model and a final model. All the control variables described above are in both the selection and final models, along with industry and year fixed effects. In 
addition, the S\&PTSX indicator variable is in the selection models but not in the final models, and the inverse Mills ratio from the first stage is in the final stage of the Heckman model. When the sample is all Canadian firms, the treatment variable of interest is the indicator for a Quebec firm $(Q C)$; if there is an additional bias against Quebec firms over ROC firms, then the coefficient on $Q C$ will be positive in the selection model (indicating that zero holdings are more likely), and negative in the final model (indicating that holdings are lower for Quebec firms than ROC firms).

We compute standard errors clustered at the year and industry level, allowing for correlation in residuals within years and industries. Note that this is considerably more conservative than clusters at the firm and year level. Finally, although we typically have directional hypotheses, we report p-values for two-tailed tests.

\subsection{THE SAMPLE}

We begin by identifying all firms headquartered in Canada and listed on the Toronto Stock Exchange (COMPUSTAT EXCHG=7) between the years 2000 and 2012, resulting in an potential sample of 13,673 firm-years, representing 2094 unique firms, of which 233 are located in Quebec. After requiring that the firm-years in our sample have the necessary data to construct our independent variables we have 9495 firm-years, and after removing companies with a stock price less than $\$ 1.00$ we have 8089 firm-years, with 1249 firmyears in Quebec and 6840 firm-years in the ROC.

We collect institutional holding information from the Thomson Financial Service database available from WRDS. For US institutional holdings, we use the S34 file (previously known as the Spectrum database). The S34 file is based on the 13-f quarterly holdings information filed by Investment Companies with the SEC. Rule 13(f) requires 
institutions managing more than $\$ 100$ million in equity to report their investment positions in all the "Section 13(f) securities" with holdings greater than 10,000 shares or $\$ 200,000$ in market value. Section 13(f) securities include all exchange-traded securities, including exchange-traded foreign company securities. It is also common for US institutional investors to voluntarily report holdings for firms not traded on US exchanges; roughly one third of our Canadian firm-years held by US investors fall into this category. The voluntary nature of this data would only bias our results if US institutional investors systematically reported Quebec firm ownership differently than ROC firm ownership. Intersecting the Canadian firm sample with the US institutional holdings yields a sample of 2956 firm-years with positive US institutional holdings, although we retain the zero holding observations for most of our tests.

For British and French institutional ownership data in Canada, we rely on the Thomson Financial Services S12 file, which reports holdings of mutual funds. ${ }^{14}$ The source data for this file is primarily the semi-annual SEC N-30D and N-30Q filings that contain reports to shareholders of the mutual fund. Thomson also contacts mutual funds directly to update their data. The S12 file contains data for the 3000 largest global funds that have any holdings in US exchange-traded or Canadian exchange-traded firms. Intersecting this institutional holding data with the Canadian firm sample results in a British investor sample of 2778 firm-years with non-zero holdings and a French sample of 1462 firm-years with non-zero holdings (as described in Table 8 and discussed later).

\footnotetext{
${ }^{14}$ Because mutual funds are just one type of investment company (bank trusts, for example, are another type of investment company), the S12 file is not directly comparable to the S34 file. Further, the holdings reported in the S34 file are aggregated across all funds under a manager that may be individually reported in the S12 file.
} 


\section{Results}

\subsection{US INSTITIONAL INVESTOR BIA AGAINST QUEBEC VERSUS THE REST OF CANADA}

Table 2 panel A describes the full Canadian firm sample and panel B describes the subsample with non-zero US institutional investor holdings. Initial evidence of the US investor bias against Quebec is seen in the first row of both panels..$^{15}$ For the full sample, the mean PCT_US is 3.9 percent for Quebec firms and 5.2 percent for ROC firms; for the subsample with non-zero holdings, the mean US ownership is 11.8 percent for Quebec firms and 13.9 percent for ROC firms. The comparison is relatively more extreme for medians; for the non-zero holding sample the median ownership is 2.3 percent for Quebec firms and, at 4.7 percent, is more than double for ROC firms. The second row of each panel shows that, for $R P W_{-} U S$, the pattern across Quebec and the ROC is the same, although the differences in means are not significant. Table 2 panel B shows a suggestive pattern in the distribution of relative portfolio weights in the sample of firms with positive values. The median $R P W_{-} U S$ for the Quebec firms is 0.572 , implying that, relative to their weight in the Canadian market, Quebec firms are under-weighted by almost 50 percent in US institutional investors' Canadian portfolios. In contrast, the median ROC firm has a relative portfolio weight of 1.269 , implying that it is over-weighted by almost 27 percent in US institutional investors' Canadian portfolios.

Examining the control variables in panel A of Table 2, we see many firm-specific characteristics of Quebec firms that might deter institutional investment relative to firms in the ROC. Quebec firms are less likely to be cross-listed in the US, they have slower growth,

\footnotetext{
${ }^{15}$ The relative sample sizes in panel A and panel B suggest that US institutional investors are more likely to have non-zero holdings in ROC firms than in Quebec firms; comparing across panels, 33 percent of Quebec firms have non-zero US investment while 37 percent of the ROC firms have non-zero US investment.
} 
lower past stock returns, and are less likely to employ a BIG4 auditor. These results emphasize the importance of controlling for firm-specific characteristics that might impact foreign investor holdings quite apart from the foreign investor bias (as discussed in Dahlquist and Robertsson 2001). Interestingly, many of these differences become insignificant once the sample is limited to only non-zero institutional holdings, as seen in panel B of Table 2. This suggests that US institutional investors use these variables to select the subset of Canadian firms to invest in, and this homogenizes the sample of nonzero holdings to some degree. Notably, there is no significant difference in the mean size of the Quebec firm and the ROC firm, as seen in both panel A and panel B. This is important because, if it was the case that Quebec firms were significantly larger than ROC firms, and if US institutional investors held equally-weighted as opposed to value-weighted portfolios, then we would observe lower percentage ownership and lower relative portfolio weights in Quebec firms.

Table 3 gives correlations between the variables in our study. Not surprisingly, our two dependent variables are highly correlated. Examining the correlations of PCT_US and $R P W_{-} U S$ with the other variables in the study shows that holdings are significantly positively correlated with whether the firm has a US segment, whether it is cross-listed in the US, firm size, and the number of analysts following the firm. There are also a number of significant correlations between the control variables. While the control variables are not central to the main message of the paper, these high correlations may cause these variables to have unexpected signs in the multivariate models.

To assess the US investor's bias against Quebec firms versus ROC firms, while controlling for the differences in firm characteristics, we estimate the zero-inflated beta model for $P C T_{-} U S$ and the two-stage Heckman model for $R P W_{-} U S$, as described above. 
Recall that positive coefficients in the selection models indicate that it is more likely to be an observation with zero holdings, while a positive coefficient in the final model indicates that the holdings are increasing in the variable. The first two columns of Table 4 give the results for the zero-inflated beta model. As seen in the first column, after controlling for many firm-specific characteristics, the probability that $P C T_{-} U S=0$ is significantly higher for Quebec firms than for ROC firms. The significantly negative coefficient on $Q C$ in the second column shows that, after controlling for selection, and all the firm-specific variables, Quebec firms have a significantly lower percentage of shares held by US investors than ROC firms.

The coefficients in the zero-inflated beta model, once raised exponentially, are the odds ratio in the selection model and the proportions ratio in the final model. ${ }^{16}$ Consequently, the 0.277 coefficient on $Q C$ in the selection model means that, after controlling for the other variables in the model, the odds of being in the zero-holding sample are 32 percent higher for a Quebec firm than for a ROC firm $(\exp (0.277)=1.32)$. Similarly, the -0.445 coefficient on $Q C$ in the final model means that, after controlling for the other variables in the model, the proportion of US investor ownership to non-US investor ownership is 35.9 percent lower for Quebec firms than for ROC firms (exp($0.445)=0.641,0.641-1=-.359)$. In sum, the US institutional investor bias against Quebec firms causes them to invest in substantially fewer Quebec firms than ROC firms and, when they invest, to invest in substantially smaller fractions of Quebec firms than ROC firms.

${ }^{16}$ As shown in Appendix 1, the coefficient on $Q C$ in the final stage model is $\beta_{Q C}=\log \left(\frac{\mu_{Q} /\left(1-\mu_{Q}\right)}{\mu_{R O C} /\left(1-\mu_{R O C}\right)}\right)$, where $\mu_{\mathrm{Q}}$ is the estimated PCT_US for a Quebec firm and $\mu_{\mathrm{Roc}}$ is the estimated $P C T_{-} U S$ for a ROC firm, and so the exponentiated value of the coefficient is the proportions ratio. 
The results for the two-stage Heckman model, given in the third and fourth columns of Table 4 mirror the results from the zero-inflated beta model. The relative portfolio weight is significantly more likely to be zero for Quebec firms than for ROC firms and, when the weight is positive, it is significantly smaller for Quebec firms than for ROC firms. The coefficient of -2.174 in the final model is economically significant as well. In the sample with positive $R P W_{-} U S$, the relative portfolio weight for the mean Quebec firm is close to the mean ROC firm (7.016 and 7.664, respectively, as seen in Table 2, panel B). However, once the firm-specific controls are added to the model, and the selection effect is controlled for with a highly significant inverse Mills ratio, the Quebec firms' relative portfolio weights are 2.174 lower than the ROC firms' relative portfolio weights. In sum, the results for $R P W_{-} U S$ echo the results for PCT_US; consistent with hypothesis one, US institutional investors have a bias against Quebec firms that is significantly greater than the bias against ROC firms.

Both models in Table 4 include indicators for provincial incorporation (PROV_INCP), US cross-listing (USCROSS), and a US segment (USSEGMENT), as well as the provincial tax

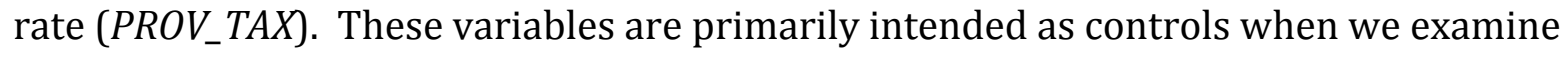
within-Quebec variation in the foreign investor bias, but we include them in the full sample models for completeness. Across the full sample of Canadian firms, US institutional investors are more likely to hold greater percentages of US cross-listed firms and firms with US segments, as seen in column 2, and they are less likely to have zero holdings in these firms, as seen in column 1 . The results for the relative portfolio weights are less clear; the selection model shows US cross-listed and US-segment firms are less likely to have zero US holdings but these variables are insignificant in the final model. Finally, column 2 shows that PCT_US is significantly lower for firms in provinces with higher tax rates. 
The other control variables behave largely as expected in the PCT_US model (not surprisingly because $P C T_{-} U S$ and the control variables are both taken from Bradshaw et al. 2004). US investor ownership increases with firm size (SIZE), with analyst coverage (NANLST), and decreases with the dividend yield (DP). Inconsistent with Bradshaw et al. (2004), ownership decreases with the raw stock return (RRET) and with the use of a BIG4 auditor (BIG4). Interestingly, these variables behave largely as expected for $R P W_{-} U S$ in the first stage of the Heckman model, but are generally insignificant in the final model. Finally, the exclusion restriction variable, $S \& P T S X$, is significant and negatively related to being a zero-holding observation, as expected.

Table 5 reports two different specification checks for each model. First, it is possible that the negative Quebec bias is actually driven by a positive Ontario bias. The Ontario Securities Act has been interpreted as giving legal standing to buyers or sellers residing outside Ontario as long as the issuer is an Ontario firm (McCloskey 2001). Further, the Toronto Stock Exchange resides in Ontario, and its rules may afford investors additional legal protection. Finally, Ontario is the largest Anglophone province. If these factors cause US investors to have a positive bias towards Ontario firms, it may induce a negative bias against Quebec firms. To rule out this alternative explanation, we re-estimate our models after excluding Ontario firms from the sample. The results for $P C T_{-} U S$, given in columns 1 and 2 , show that the coefficient estimates and significance levels of $Q C$ are very similar to those reported for the full sample. The results for $R P W_{-} U S$, given in Columns 5 and 6 , are also consistent with the results for the full sample, although the coefficient on $Q C$ gained some significance in the selection model but lost some significance in the final model.

The second specification check in Table 5 is to estimate simple OLS regressions. Note that there is no selection model and the predicted coefficient on $Q C$ is negative for the 
full sample and the restricted sample of non-zero holdings. As seen in column 3,PCT_US is 2.7 percent lower for Quebec firms than for ROC firms in the full sample, and is 6.3 percent lower when the sample is restricted to those firms with non-zero holdings, as seen in column 4. Finally, the results for $R P W_{-} U S$ are given in column 7 for the full sample and in column 8 for the non-zero holdings sample; the coefficient on $Q C$ is significantly negative in both cases.

In terms of the other firm choices that may influence institutional investment, USCROSS and USSEGMENT continue to remain significant for most of the columns in Table 5. The simple OLS with the non-zero holding sample gives the easiest coefficients to interpret. In column 4 we see that cross-listing increases the percent held by 8.2 percent and having a US segment increases the percent held by 7.1 percent; both values are only slightly higher than the impact of being located in Quebec (in absolute value). In terms of relative portfolio weights, column 8 shows that cross-listing increases the weight in the US investor portfolio, relative to the firm's weight in the country by 5.168 , and having a US segment increases it by 4.141. Again, these effects are only slightly more extreme than the effect of being located in Quebec, and help to put the bias against Quebec firms in perspective.

The most significant control variable in the selection models given in Table 4 is firm size. Accordingly, in Table 6 we match on size. Matching allows a more general relation between size and the dependent variable than the zero-inflated beta model or two-stage Heckman model afford. For each firm-year with non-zero holdings we match the Quebec firm with the closest firm in the ROC in terms of its market value; the resulting sample has 416 observations from Quebec and 416 observations from the ROC. As seen in the table, the coefficient for $Q C$ is -0.596 , somewhat more negative than the comparable coefficient in 
column 2 of Table 4 or column 2 of Table 5. The magnitude of this result is striking - a firm in Quebec has a proportion of US ownership to non-US ownership that is 45 percent lower than the size-matched firm in the ROC $(\exp (-0.596)=0.55,0.55-1=0.45)$. For the $R P W_{-} U S$, the coefficient on $Q C$ is -3.879, roughly 78 percent more negative than the comparable coefficient in column 4 of Table 4; the portfolio weight US institutional investors put on Quebec firms, relative to their weight in the Canadian market, is 3.879 lower than the relative weight they place on a size-matched firm in the ROC.

In sum, US institutional investors exhibit a significant bias against firms located in Quebec relative to the ROC, consistent with the first hypothesis. Despite the similarities in physical distance to the US, the bilingual publication of important disclosure documents, and the same accounting rules across Canadian provinces, US investors view Quebec firms less favourably than ROC firms, both in terms of the percent of shares they hold and in the relative weight they place on the firm in their Canadian portfolio. Further, the results do not appear to be driven by differences in investor protection, insofar as controlling for provincial incorporation, US cross-listing, and removing Ontario from the sample, did not change the results.

\subsection{DOES THE INVESTOR BIAS AGAINST QUEBEC HAVE A BASIS IN LANGUAGE?}

We have documented a large US investor bias against Quebec firms relative to ROC firms. In this section we ask if any part of the US investor bias against Quebec firms is due to the use of the French language in Quebec. We approach this problem by 1) examining the impact of variation in Quebec firms' French internet presence on the US investor bias, and 2) by contrasting the bias of British investors and French investors. 
To measure variation in language at the firm level we create a measure of a firm's French language online presence, labeled FRENCHNESS. We construct this measure by counting the number of French and English documents that result from an Advanced Google search of the company's name during each fiscal year: FRENCHNESS is the ratio of French documents to the sum of French and English documents. FRENCHNESS is a proxy for the relative gross information production about the firm in each language. We make no effort to eliminate redundant documents in the count, reasoning that they represent the redistribution of information to different audiences. To control for the total amount of information production, we also create the variable $W E B$ as the log of one plus the total number of documents in both languages (i.e. the log of the denominator of FRENCHNESS). While the idea behind FRENCHNESS is relatively easy to describe, the actual Advanced Google search process is complicated, and is described in Appendix 2. We begin with the sample of 416 Quebec firm-years with non-zero US holdings, but eliminate 30 firm-years because our search results did not yield any documents that could clearly be associated with a specific year. The result is a sample of 386 Quebec firm-years. The median value for FRENCHNESS is 0.259 , and it ranges from 0 to 0.670 (untabulated).

Table 7 divides the Quebec firm sample by FRENCHESS above and below the median and gives descriptive statistics for each group. The third row in the table shows that US investor's hold 7.4 percent of the float in high FRENCHNESS firms and 13.4 percent of the float for low FRENCHNESS firms, on average, and the difference is significant. The relative portfolio weight is also lower in high FRENCHNESS firms, although the difference is not significant. Table 7 also shows other important differences between high and low FRENCHNESS firms. The frequency of provincial incorporation (in this case, the Quebec Company Act) is significantly higher for high FRENCHNESS firms, and the frequency of US 
cross-listing is significantly lower. Because these factors can influence US institutional investor holdings, but are unrelated to language, they will need to be controlled in the multivariate models. Finally, there is no significant difference in the sizes of firms with high or low FRENCHNESS.

Table 8 fits a beta model for PCT_US and an OLS model for RPW_US for the non-zero US investor holdings of Quebec firms (because we begin with the non-zero holdings, we do not need a first-stage selection model). The first row of the table shows that US holdings are significantly negatively related to a Quebec firm's FRENCHESS. The coefficient of -0.671 in the PCT_US implies that the ratio of US investor holdings to non-US investor holdings is 4.9 percent lower for a 10 percent increase in FRENCHNESS $(\exp (-0.671)=.51, .51-1=.49$, times a treatment effect of $.10=4.9$ percent). The coefficient of -7.911 in the $R P W_{-} U S$ model is also impressive, given that the mean of RPW_US is 5.471 for low FRENCHNESS firm-years and 6.432 for high FRENCHNESS firms. A 10 percent increase in FRENCHNESS is associated with a 79.11 percent reduction in the relative portfolio weight in the US investor's Quebec portfolio. Of the other firm choice variables that vary within Quebec, PROV_INCP, USCROSS, and USSEGMENT, only cross-listing is significant. In sum, after controlling for all the firm-level characteristics, the degree of FRENCHNESS displayed by a Quebec firm has a significant influence on its US institutional investor holdings. These results are consistent with our second hypothesis.

Our second approach to identifying the language/culture contribution to the foreign investor bias is to contrast the holdings of British and French institutional investors. As discussed in the last section, this treatment provides a high contrast in the alignment of language between the investor and the Quebec firm, significantly increases the geodesic distance from Canada, but keeps the distance from Canada approximately equal for the two 
investor locations. ${ }^{17}$ We caution, however, that the data on institutional holdings of British and French investors is not nearly as complete the US institutional holdings data; consequently, the overall level of investment is likely to be understated.

Table 9 gives descriptive statistics for the samples that intersect Canadian firms with institutional investors from the UK (panel A) and from France (panel B); we only tabulate these statistics for the non-zero holdings sample but include the zero holdings data in all the models that follow. Because institutional investors are much larger in the UK than in France, it isn't surprising that the British hold more of the float in both Quebec firms and ROC firms than the French do, as seen by comparing the first row in each panel. However, our hypothesis is that the relative bias will be smaller in France than the UK, as is indeed the case. To see this, compare the difference in British and French holdings in Quebec $\left(P C T_{-} U K-P C T_{-} F R A N C E=0.67\right.$ percent -0.14 percent $=0.53$ percent $)$ with the difference in their holdings in the ROC $\left(P C T_{-} U K-P C T_{-} F R A N C E=1.21\right.$ percent -0.27 percent $=0.94$ percent); the French are much closer to the British in their holdings of Quebec firms than in their holdings of ROC firms. Interestingly, the relative portfolio weights of French investors are greater than the weights of British investors in both Quebec and the ROC basically, French investors place smaller but more concentrated bets in Canada. More importantly, the difference in the relative portfolio weights is greater in Quebec $\left(R P W_{-} U K-\right.$ $\left.R P W_{-} F R=11.372-18.739=-7.367\right)$ than it is in the ROC $\left(R P W_{-} U K-R P W_{-} F R=25.335-\right.$ $27.135=-1.800$ ). While French investors place only slightly larger weights on ROC firms

\footnotetext{
17 Obviously investors in France and the UK differ greatly in their use and understanding of the French language. But, as we have discussed, language is tied up with culture. Using the four Hofstede measures of culture once again, the Euclidian distance between France and Quebec is 30 while the distance between the UK and Quebec is 41.
} 
than British investors, they place substantially larger weights on Quebec firms than British investors do.

The other differences in firm characteristics between Quebec and the ROC have similar patterns across the two panels of Table 9. In both samples, the firms in Quebec are more likely to have a European segment (EUSEGMENT), have a lower provincial tax rate $\left(P R O V_{-} T A X\right)$, and are less likely to be incorporated under provincial law (PROV_INCP), all of which should lead to greater institutional ownership. Working against this, however, is the fact that in both samples, firms in Quebec are less likely to be cross-listed on a European exchange (EUCROSS).

To compare the relative bias against Quebec between the two investor groups, we begin with the full sample of 8089 Canadian firms-years, of which 2900 firm-years have non-zero holdings from either British or French investors. We then subtract the French value from the British value to create two new dependent variables, $P C T D I F=P C T_{-} U K-$ $P C T_{-} F R$, and $R P W D I F=R P W_{-} U K-R P W_{-} F R$.

Our first model recognizes that, because the majority of observations are zero (both the British and French values are zero), we again have a selection problem. To control for this we estimate a two-stage Heckman model, where the first stage uses EUCROSS and EUSEGMENT in addition to the same set of variables that were in the first stage models given for PCT_US and RPW_US in columns 1 and 3, respectively, in Table 4. The first stage uses the full sample of 8089 observations. For brevity, we only report the final stage model results in Table 10. As seen in column 1, the coefficient on $Q C$ is significantly negative; the difference between the percent of float held by British investors and French investors is smaller for Quebec firms than ROC firms. As a robustness test we also estimate OLS regressions on the full sample of firms, and on the subsample of non-zero holdings. The 
treatment variable $Q C$ is again significantly negative in both regressions, as seen in columns 2 and 3. Columns 5, 6, and 7 repeat the above analysis using the difference in relative portfolio weights between the two groups of investors (RPWDIF). In all specifications the coefficient on $Q C$ is significantly negative, implying that British investors have a bigger bias against Quebec firms relative to ROC firms than French investors.

The final analysis in Table 10 takes a different approach to comparing the relative investor biases between British and French investors. PCTDIF and RPWDIF show the difference between French and British investors' response to Quebec firms and ROC firms, but they don't reveal the level of each groups' bias against each firm location. To investigate this issue, rather than taking the difference in their percentage holdings or relative portfolio weights, we use the original dependent variables $P C T_{-} U K, P C T_{-} F R A N C E$, $R P W_{-} U K$ and $R P W_{-} F R A N C E$ and stack all observations with non-zero holdings from either British or French investors. In effect, one observation in this analysis is a firm-yearinvestor location. We then use an indicator variable FRANCE to identify the investor location (FRANCE equals one when the investor is in France and equals zero when the investor is in the UK). Thus, different combinations of $Q C$ and FRANCE pick out the values for different firm locations and investor locations while controlling for all the previously discussed variables. Examining the first row of columns 4 and 8 in Table 10 shows the generic bias against Quebec; the coefficient on $Q C$ is significantly negative in both regressions. Of more interest, however, is the coefficient on the interaction between $Q C$ and FRANCE; in both models the interaction is significantly positive. Controlling for the generic bias against Quebec $(Q C)$ and for any difference in the Canada-wide level of investment by each investor location (FRANCE), French investors hold significantly more of the float and place larger portfolio weights on Quebec firms than ROC firms ( $\left.Q C^{*} F R A N C E\right)$. 
To illustrate the results for the stacked regressions in columns 4 and 8 of Table 10, consider the estimated effects for different combinations of investor and firm locations. Beginning with the values for percent holdings in column 4, label the estimated British holdings in ROC firms (FRANCE $=0$ and $Q C=0$ ) as INTCP (basically the sum of the intercept and all the fixed effects). The estimated British holdings in Quebec firms (FRANCE $=0$ and $Q C=1$ ) is then INTCP-0.003; British investors have a bigger bias against Quebec firms than against ROC firms. Similarly, the estimated French holdings in ROC firms is INTCP -0.010 (FRANCE $=1$ and $Q C=0$ ), and the estimated French holdings in Quebec firms is INTCP-0.003$0.010+0.005=I N T C P-0.008(F R A N C E=1$ and $Q C=1)$. Thus, French investors have a smaller bias against Quebec firms than against ROC firms. The same exercise for relative portfolio weights using the estimates from column 8 gives similar results. British investors have a bigger bias against Quebec firms than ROC firms, and French investors have a bigger bias against ROC firms than Quebec firms.

In sum, comparing the behaviour of British and French investors offers a good contrast in the alignment of language between the investor and the firm while greatly increasing the distance from Canada, and yet holding it roughly equal between investor groups. It also holds constant Quebec-specific forces, such as political risk or poor investor protection. We find that French investors have a significantly smaller bias than British investors against Quebec firms relative to ROC firms. These results are consistent with our third hypothesis.

\section{Conclusion}

In the search for the root cause of the foreign investor bias against domestic firms, our results indicate that foreign investors are sensitive to differences between their 
domestic language and the language used in the location of a foreign investment. This bias has a significant impact on firms in Quebec. US institutional investors invest significantly less in Quebec firms than in firms located elsewhere in Canada, and at a rate that varies significantly with the "Frenchness" of the Quebec firm. We also find that French investors are significantly less biased against Quebec firms than are British investors, adding further evidence to the hypothesis that linguistic differences contribute significantly to the foreign investor bias. 


\section{Appendix 1}

This appendix borrows heavily from Cook et al. (2008) and the references therein. The zero-inflated beta model assumes the following density for the proportion $y_{i}$ of foreign ownership:

$g\left(y_{i} ; \delta, \mu, \phi\right)=\left\{\begin{array}{c}\delta \text { if } y_{i}=0 \\ (1-\delta) f\left(y_{i} ; \mu, \phi\right) \text { if } 0<y_{i}<1\end{array}\right.$

where $f\left(y_{i} ; \mu, \phi\right)$ is a beta density defined on $0<y_{i}<1$, given as

$f\left(y_{i} ; u, \phi\right)=\frac{\Gamma(\phi)}{\Gamma(\mu \phi) \Gamma((1-\mu) \phi)} y_{i}^{\mu \phi-1}\left(1-y_{i}\right)^{(1-\mu) \phi-1}$.

where $0<\mu<1$ and $\phi>0 ; \mu$ is the location parameter, with $E\left(y_{i}\right)=\mu$ and $\phi$ is the precision parameter, with $\mathrm{V}\left(y_{i}\right)=\frac{\mu(1-\mu)}{\phi+1}$. Thus, for the density g,

$\mathrm{E}\left(y_{i}\right)=(1-\delta) \mu$ and $\mathrm{V}\left(y_{i}\right)=(1-\delta) \frac{\mu(1-\mu)}{\phi+1}+\delta(1-\delta) \mu^{2}$

The expression for $\mathrm{E}\left(y_{i}\right)$ illustrates how failing to account for the mass of observations at zero will lead to overstated estimates of the proportion. The expression for $\mathrm{V}\left(\mathrm{y}_{i}\right)$ illustrates that the variance increases with the mean, a distributional feature that the OLS model cannot accommodate. The advantage of assuming the dependent variable has this density is that it allows an arbitrarily large mass point at zero through the parameter $\delta$, and is has a very flexible shape for values greater than zero as determined by the $u$ and $\phi$ parameters. For instance, the beta density can be uniform $(\mu=1 / 2, \phi=1)$, can descend monotonically over the interval (e.g. $\mu=1 / 4, \phi=4$ ), or be single-peaked (e.g. $\mu=1 / 2, \phi=4$ ). ${ }^{18}$

Next we need to describe how the independent variables map into the dependent variable. There are two parts to this. First, to estimate whether $y_{i}=0$ or $y_{i}>0$ the model assumes a cumulative logistic function mapping the data vector $X_{i}$ with weight parameters $A$ into the probability of $y_{i}=0$, as

$\operatorname{Prob}\left(y_{i}=0\right)=\delta=\frac{e^{X_{i}^{\prime} A}}{1+e^{X_{i}^{\prime} A}}$

If $y_{i}>0$ the model maps the data vector $Z_{i}$ with coefficient weights $B$ to the conditional mean parameter $u_{i}$, as

$E\left(y_{i} \mid y_{i}>0\right)=\mu_{i}=\frac{e^{Z_{i}^{\prime} B}}{1+e^{Z_{i}^{\prime} B}}$

\footnotetext{
18 One may be tempted to use a Tobit model to handle the mass of zeros. However, the Tobit model is designed for cases where the data is censored at zero; that is, the true value is negative but the research only observes these values as being censored to zero. That is not the case for proportions. See Madalla (1991) for an extended discussion of this issue.
} 
Importantly, note that the two parts of the model can be estimated on different independent variable vectors $X_{i}$ and $Z_{i}$, and even if $X_{i}=Z$, as will be the case in our analysis, the model allows different estimated weights $A$ and $B$.

The data vectors $X_{i}$ and $Z_{i}$ and weight vectors $A$ and $B$ combine to determine $\mu_{i}$ and $\delta$ in the density of $y_{i}$ given above. The maximum likelihood estimates of $A$ and $B$ are those that maximize the joint density of the sample $\left(y_{i}, X_{i}, Z_{i}\right)$. The estimation is performed using the ZOIB module in STATA, which allows for fixed effects and clustered standard errors.

As with any logistic function, the exponentiated coefficients from A3 are odds ratios; similarly, the exponentiated coefficients from A4 are ratios of proportions. That is,

$e^{Z_{i}^{\prime} B}=\frac{\mu_{i}}{1-\mu_{i}}$

In the context of this study, denote the coefficient on the indicator variable $Q C$ as $\beta_{Q C}$ and rewrite the LHS of A5 as $e^{\beta_{Q C}} e^{Z_{i}^{\prime} B}$ when $Q C=1$ (the firm is in Quebec) and $e^{Z_{i}^{\prime} B}$ when $Q C=0$ (the firm is in the Rest of Canada). Taking the ratio gives

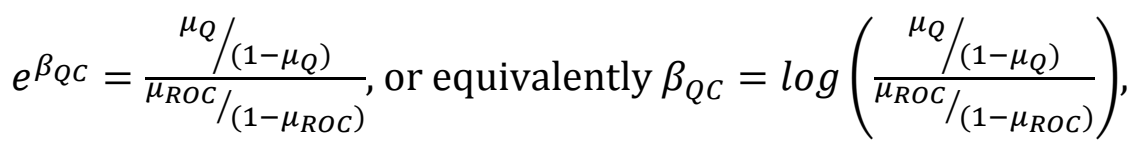

where the subscript on $\mu$ indicates whether the firm is in Quebec (Q) or the Rest of Canada (ROC). As an example, in Table 4, column 2, the coefficient on QC is -0.445 , and so the exponentiated value is 0.641 . This means that, after controlling for the other variables in the model, the ratio of US investor ownership to non-US investor ownership is 35.9 percent lower for Quebec firms than for ROC firms. 


\section{Appendix 2}

We use Advanced Google Search to construct both WEB and FRENCHNESS for our sample of Quebec firm-years. In the search we stipulate that the source documents be a) from Canada, b) in the year that corresponds to the firm's fiscal year, c) in the French language, and then separately, in the English language. The search string is for the exact string of the company's name. We first investigate how the company's name appears on the company website and in popular news sources to develop a suitable search string (often ending with the suffix 'Inc.'). We require that the search string yields the company website in the first page of the search results, and manually check that the search results indeed correspond to the company. Once the correct search string for a company is found, we identify the documents generated about the company in each language for each fiscal year. If a company changes its name over the sample period, we make appropriate changes in the search string so that we use the correct name when searching for documents in prior fiscal years. The results are then manually checked to eliminate matches that do not correspond to the firm (typically occurring on the last few pages of the search). All redundant documents are counted, reasoning that these represent rebroadcasting of information to different audiences.

A minor problem with replicability occurs because the Google search algorithm is dynamic, and proprietary. To limit this problem, the search was conducted on a computer with all browser data erased after each search, and the location of the user blocked. All searches were performed in the month of November, 2012, but the same procedure conducted at a later point in time may yield slightly different results. The results for our sample are available on request. 


\section{References}

Aggarwal, R., A. Colm, B. Kearney, and B. Lucey. 2012. Gravity and culture in foreign portfolio investment. Journal of Banking \& Finance 36:525-538.

Ahearne, A., W. Griever, and F. Warnock. 2004. Information costs and home bias: an analysis of US holdings of foreign equities. Journal of International Economics 62:313-336.

Andrade, S., and V. Chhaochharia. 2010. Information Immobility and Foreign Portfolio Investment. The Review of Financial Studies, 23:2429-2463.

Attig, N. 2007. Excess control and the risk of corporate expropriation: Canadian evidence. Canadian Journal of Administrative Sciences 24:94-106.

Aviat, A., and N. Coeurdacier. 2007. The geography of trade in goods and asset holdings. Journal of International Economics 71:22-51.

Barkema, H. and F. Vermeulen. 1997. What differences in the cultural backgrounds of partners are detrimental for international joint ventures? Journal of International Business Studies 28: 845-864.

Beaulieu, M., J. Cosset, and N. Essaddam. 2006. Political Uncertainty and Stock Market Returns: Evidence from the 1995 Quebec Referendum. The Canadian Journal of Economics 39:621-641.

Beugelsdijk, S., and B. Frijns. 2010. A cultural explanation of the foreign bias in international asset alocation. Journal of Banking and Finance 34:2121-2131.

Boubraki, N., Y. Bozec, C. Laurin, and S. Rousseau. 2011. Incorporation Law, Ownership Structure, and Firm Value: Evidence from Canada. Journal of Empirical Legal Studies 8:358383.

Bradshaw, M., B. Bushee, and G. Miller. 2004. Accounting Choice, Home Bias, and U.S. Investment in Non-U.S. Firms. Journal of Accounting Research 42:795-841

Brouthers, K. and L. Brouthers. 2001. Explaining the national cultural distance paradox. Journal of International Business Studies 32:177-189.

Bushee, B. 1998. The Influence of Institutional Investors on Myopic R\&D Investment Behavior. The Accounting Review 73:305-33.

Bushee, B. 2001. Do Institutional Investors Prefer Near-Term Earnings over Long-Run Value? Contemporary Accounting Research 18:207-46.

Canadian Securities Administrators. 2014. Pan-Canadian Passport as retrieved on April 2014 from http://www.securities-administrators.ca/aboutcsa.aspx?id=96. 
Cao, H., B. Han, D. Hirshleifer, and H. Zhang. 2011. Fear of the Unknown: Familiarity and Economic Decisions. Review of Finance 15:173-206.

Chan, K., V. Covrig, and L. Ng. 2005. What Determines the Domestic Bias and Foreign Bias? Evidence from Mutual Fund Equity Allocations Worldwide. The Journal of Finance 60:14951534.

Cook, D., R. Kieschnick and B. McCullough. 2008. Regression analysis of proportions in finance with self-selection. Journal of Empirical Finance 5:860-867.

Covig, M., M. DeFond, and M. Hung. 2007. Home Bias, Foreign Mutual Fund Holdings, and the Voluntary Adoption of International Accounting Standards. Journal of Accounting Research 45:45-70.

Dahlquist, M., L. Pinkowitz, R. Stulz, and R. Williamson. 2003. Corporate governance and the home bias. Journal of Financial and Quantitative Analysis 38(1): 87-110.

Dahlquist, M., and G. Robertsson. 2001. Direct foreign ownership, institutional investors, and firm characteristics. Journal of Financial Economics 59:413-440.

Daude, C., and M. Fratzscher. 2006. The Pecking Order of Cross-border Investment. European Central Bank Working Paper Series: 590, Frankfurt.

DeFond, M., X. Hu, M. Hung, and S. Li. 2011. The impact of mandatory IFRS adoption on foreign mutual fund ownership: The role of comparability. Journal of Accounting and Economics 51(3):240-258.

Ferrari, S., and F. Cribari-Neto. 2004. Beta regression for modeling rates and proportions. Journal of Applied Statistics 31:799-815.

French, K., and J. Poterba. 1991. Investor diversification and international equity markets. American Economic Review 81(2):222-226.

Graham, R., C. Morrill, and J. Morrill. 2012. Does it matter where assets are held and income is derived? Further evidence of differential value relevance from Quebec. Journal of International Accounting, Auditing and Taxation 21(2):185-197.

Grinblatt, M., and M. Keloharju. 2001. How distance, language, and culture influence stockholdings and trades. Journal of Finance 56(3):1053-1073.

Heckman, J. 1979. Sample selection bias as a specification error. Econometrica 47:153-161.

Hofstede, G., G. J. Hofstede, and M. Minkov. 1997. Cultures and organizations. New York: McGraw-Hill. 
Kang, J. 1997. Why is there a home bias? An analysis of foreign portfolio equity ownership in Japan. Journal of Financial Economics 46(1): 3-28.

King, M., and D. Segal. 2009. The Long-Term Effects of Cross-Listing, Investor Recognition, and Ownership Structure on Valuation. The Review of Financial Studies 22(6):2393-2421.

Kieschnick, R., and B. McCullough. 2003. Regression Analysis of variates observed on $(0,1)$ : percentages, proportions, and fractions. Statistical Modeling 3:193-213.

Kogut, B., and H. Singh. 1998. The Effect of National Culture on the Choice of Entry Mode. Journal of International Business Studies 19(3):411-432.

Lane, P., and G. Milesi-Ferretti. 2008. International investment patterns. Review of Economics and Statistics 90:538-549.

Lennox, C., J. Francis, and Z. Wang. 2012. Selection Models in Accounting Research. The Accounting Review. 87:589-616.

Loree, D., and S. Guisinger. 1995. Policy and non-policy determinants of US equity foreign direct investment. Journal of International Business Studies 26:281-299.

La Porta, R., F. Silanes, A. Shleifer, and R. Vishny. 1997. Legal Determinants of External Finance. Journal of Finance 52:1131-1150.

Lundholm, R., R. Rogo, and J. Zhang. 2014. Restoring the tower of Babel: How foreign firms communicate with US investors. The Accounting Review 89(4):1453-1485.

Maddala, G., 1991. A perspective on the use of limited-dependent variables in accounting research. The Accounting Review 66:786-807.

McCloskey, M. 2001. Canada: Control Blocks retrieved on April 15, 2014 from http://www.mondaq.com/canada/x/15042/securitization+structured+finance/Control+B locks.

Merton, R. 1987. A simple model of capital market equilibrium with incomplete information. The Journal of Finance 42(3):483-510.

Portes, R., H. Rey, and Y. Oh. 2001. Information and capital flows: the determinants of transactions in financial assets. European Economic Review 45:783-796.

Portes, R., and H. Rey. 2005. The determinants of cross-border equity flows. Journal of International Economics 65(2):269-296.

Puri, P. 2009. Legal Origins, Investor Protection, and Canada. BYU Law Review 1671-1700.

Rowland, P. 1999. Transaction costs and international portfolio diversification. Journal of International Economics 49(1):145-170. 
Spamann, H. 2010. The 'Antidirector Rights Index' Revisited. Review of Financial Studies 23: 467-486.

Standard and Poor's. 2011. S\&P Global 1200 Methodology, April.

Statistics Canada. 2011. French and the francophonie in Canada. Retrieved on April 15, 2014 from http://www12.statcan.gc.ca/census-recensement/2011/as-sa/98-314-x/98-314x2011003_1-eng.cfm

Statistics Canada. 2012. Gross domestic product, expenditure-based, by province and territory. Retrieved on April 15, 2014 from http://www.statcan.gc.ca/tables-tableaux/sumsom/101/cst01/econ15-eng.htm

Tesar, L., and I. Werner. 1995. Home bias and high turnover. Journal of International Money and Finance 14(4):467-492.

Tirtiroglu, D., H. Bhabra, and U. Lel. 2004. Political uncertainty and asset valuation: evidence from business relocations in Canada. Journal of Banking and Finance 28:2237-58.

Wahid, A., and G. Yu. 2014. Accounting standards and international portfolio holdings. The Accounting Review, 89(5):1895-1930. 


\section{Table 1}

\section{Variable Definitions}

\begin{tabular}{|c|c|}
\hline Variable & Definition \\
\hline \multicolumn{2}{|c|}{ Dependent Variables } \\
\hline$P C T_{-} U S$ & $\begin{array}{l}\text { percentage ownership by U.S. institutional investors in the firm from Thomson } \\
\text { Reuters Institutional Holdings S34 file (the } 13 \mathrm{f} \text { data), defined as total number } \\
\text { of shares owned by U.S. institutions divided by the float, which is shares } \\
\text { outstanding less the number of shares held by block holders, at the end of the } \\
\text { fiscal year }\end{array}$ \\
\hline$R P W_{-} U S$ & $\begin{array}{l}\text { US investor relative portfolio weight is the weight of the firm in US investor's } \\
\text { Canadian portfolio compared to its weight in Canadian equity market. } \\
\text { Let } M V_{j}^{U S}=\text { total dollar amount invested by the US institutional investors in } \\
\text { firm j. If there are N firms in the Canadian equity market, then firm j's weight in } \\
\text { US investors' Canadian portfolio, } W_{j}^{U S}=M V_{j}^{U S} / \sum_{j=1}^{N} M V_{j}^{U S} \text {. Similarly, let } M V_{j} \\
\text { denote the market value of firm j. Then firm j's weight in the Canadian market } \\
\text { portfolio, } W_{j}^{M}=M V_{j} / \sum_{j=1}^{N} M V_{j} \text {. The relative portfolio weight of firm 'j' among } \\
\text { US investors is defined as: } W_{j}^{U S} / W_{j}^{M} \text {. }\end{array}$ \\
\hline PCTDIF & $\begin{array}{l}\text { differential ownership by the U.K. mutual funds and the French mutual funds } \\
\text { for a given firm-year, defined as PCT_UK minus PCT_FRANCE, where PCT_UK } \\
\text { and PCT_FRANCE are constructed in the same way as PCT_US described above. } \\
\text { For British and French holdings, data is available only for mutual funds, and it } \\
\text { comes from Thomson Reuters mutual fund database (i.e. the S12 file). }\end{array}$ \\
\hline$R P W D I F$ & $\begin{array}{l}\text { differential relative portfolio weight by the UK mutual funds and the French } \\
\text { mutual funds for a given firm-year, defined as RPW_UK minus RPW_FRANCE, } \\
\text { where RPW_UK and RPW_FRANCE are constructed in the same way as RPW_US } \\
\text { described above. For British and French holdings, data is available only for } \\
\text { mutual funds, and it comes from Thomson Reuters mutual fund database (i.e. } \\
\text { the S12 file). }\end{array}$ \\
\hline \multicolumn{2}{|c|}{ Variables for Canada-wide Analysis } \\
\hline$Q C$ & $\begin{array}{l}\text { indicator variable equal to } 1 \text { if the firm is headquartered in the Province of } \\
\text { Quebec [LOC=Canada and STATE=Quebec] and } 0 \text { if the firm is headquartered in } \\
\text { another Canadian province. }\end{array}$ \\
\hline S\&PTSX & $\begin{array}{l}\text { indicator variable equal to } 1 \text { if a firm is included in the S\&PTSX (previously } \\
\text { known as TSX300) index in given year, and } 0 \text { otherwise. }\end{array}$ \\
\hline USCROSS & $\begin{array}{l}\text { indicator variable equal to } 1 \text { if the firm's equity is traded in a major U.S. } \\
\text { exchange or over-the-counter bulletin board in a given year as recorded in the } \\
\text { CRSP-COMPUSTAT merged database, and } 0 \text { otherwise. }\end{array}$ \\
\hline USSEGMENT & $\begin{array}{l}\text { indicator variable equal to } 1 \text { if the firm discloses U.S. segment sales in } \\
\text { COMPUSTAT Historical Segment data, and } 0 \text { otherwise. }\end{array}$ \\
\hline PROV_INCP & $\begin{array}{l}\text { indicator variable equal to } 1 \text { if the firm is incorporated under the provincial } \\
\text { incorporation act, and } 0 \text { if the firm is incorporated under the Canadian Business } \\
\text { Corporation Act or another national regulatory regime. }\end{array}$ \\
\hline PROVTAX & $\begin{array}{l}\text { provincial marginal tax rate of the province where the firm is headquartered in } \\
\text { a given year. }\end{array}$ \\
\hline SIZE & $\begin{array}{l}\text { the logarithm of the market value of equity at the end of the fiscal year : } \\
\text { [Log(CSHO*PRCC_F)]. Reported unlogged in descriptive tables } 2 \text { and } 7 .\end{array}$ \\
\hline$A G E$ & $\begin{array}{l}\text { firm age, defined as log of one plus the number of years since a firm's first } \\
\text { appearance in COMPUSTAT fundamental file. Reported unlogged in descriptive } \\
\text { tables } 2 \text { and } 7 .\end{array}$ \\
\hline GROWTH & the one-year growth in net sales: [SALE/lag(SALE)-1] \\
\hline
\end{tabular}




\begin{tabular}{cl}
\hline ROE & $\begin{array}{c}\text { return on equity, calculated as (net income after preferred dividends } \\
\text { /beginning common equity): [(NI-DVP)/lag(CEQ)] }\end{array}$ \\
\hline the debt-to-total assets ratio, calculated as [(long-term debt + debt in current \\
liabilities)/total asset] : [(DLTT+DLC)/AT]
\end{tabular}


Table 2

Descriptive Statistics: US Institutional holdings of Canadian firms

Panel A. Full sample

\begin{tabular}{|c|c|c|c|c|c|c|c|c|c|c|c|c|}
\hline \multirow[b]{3}{*}{ PCT_US } & \multicolumn{5}{|c|}{ Quebec } & \multicolumn{5}{|c|}{ Rest of Canada } & \multirow{2}{*}{\multicolumn{2}{|c|}{$\begin{array}{c}\text { Difference } \\
\text { in Mean }\end{array}$}} \\
\hline & Count & Mean & P25 & Median & P75 & Count & Mean & P25 & Median & P75 & & \\
\hline & 1249 & 0.039 & 0.000 & 0.000 & 0.003 & 6840 & 0.052 & 0.000 & 0.000 & 0.007 & -0.012 & $* *$ \\
\hline$R P W_{-} U S$ & 1249 & 2.337 & 0.000 & 0.000 & 0.056 & 6840 & 2.846 & 0.000 & 0.000 & 0.268 & -0.509 & \\
\hline USSEGMENT & 1249 & 0.144 & 0.000 & 0.000 & 0.000 & 6840 & 0.135 & 0.000 & 0.000 & 0.000 & 0.009 & \\
\hline PROV_TAX & 1249 & 0.101 & 0.089 & 0.090 & 0.119 & 6840 & 0.116 & 0.100 & 0.118 & 0.120 & -0.016 & $* * *$ \\
\hline PROV_INCP & 1249 & 0.364 & 0.000 & 0.000 & 1.000 & 6840 & 0.672 & 0.000 & 1.000 & 1.000 & -0.308 & $* * *$ \\
\hline$A G E$ & 1249 & 14.2 & 6.0 & 11.0 & 19.0 & 6840 & 12.6 & 5.0 & 9.0 & 16.0 & 1.6 & $* * *$ \\
\hline USCROSS & 1249 & 0.300 & 0.000 & 0.000 & 1.000 & 6840 & 0.352 & 0.000 & 0.000 & 1.000 & -0.052 & $* * *$ \\
\hline$S I Z E$ & 1249 & 1852.8 & 82.2 & 284.0 & 1145.2 & 6840 & 1772.5 & 75.9 & 263.2 & 1014.8 & 80.3 & \\
\hline GROWTH & 1249 & 0.193 & -0.019 & 0.070 & 0.190 & 6840 & 0.342 & -0.027 & 0.107 & 0.342 & -0.149 & $* * *$ \\
\hline$R O E$ & 1249 & 0.055 & 0.003 & 0.110 & 0.179 & 6840 & 0.071 & -0.012 & 0.091 & 0.186 & -0.016 & \\
\hline LEVERAGE & 1249 & 0.202 & 0.040 & 0.179 & 0.320 & 6840 & 0.214 & 0.033 & 0.181 & 0.328 & -0.012 & $*$ \\
\hline$E P$ & 1249 & 0.001 & 0.002 & 0.056 & 0.085 & 6840 & 0.005 & -0.008 & 0.046 & 0.084 & -0.004 & \\
\hline $\boldsymbol{B P}$ & 1249 & 0.763 & 0.401 & 0.612 & 0.973 & 6840 & 0.727 & 0.373 & 0.603 & 0.956 & 0.036 & $*$ \\
\hline$D P$ & 1249 & 0.022 & 0.000 & 0.008 & 0.024 & 6840 & 0.032 & 0.000 & 0.005 & 0.044 & -0.011 & $* * *$ \\
\hline RRET & 1249 & 0.159 & -0.167 & 0.081 & 0.334 & 6840 & 0.225 & -0.150 & 0.116 & 0.412 & -0.066 & $* * *$ \\
\hline NANALYST & 1249 & 0.582 & 0.000 & 0.000 & 0.000 & 6840 & 0.463 & 0.000 & 0.000 & 0.000 & 0.119 & $*$ \\
\hline BIG4 & 1249 & 0.839 & 1.000 & 1.000 & 1.000 & 6840 & 0.932 & 1.000 & 1.000 & 1.000 & -0.093 & $* * *$ \\
\hline
\end{tabular}


Table 2 (Continued)

Descriptive Statistics: US Institutional holdings of Canadian firms

Panel B. Only firm-years with non-zero holdings

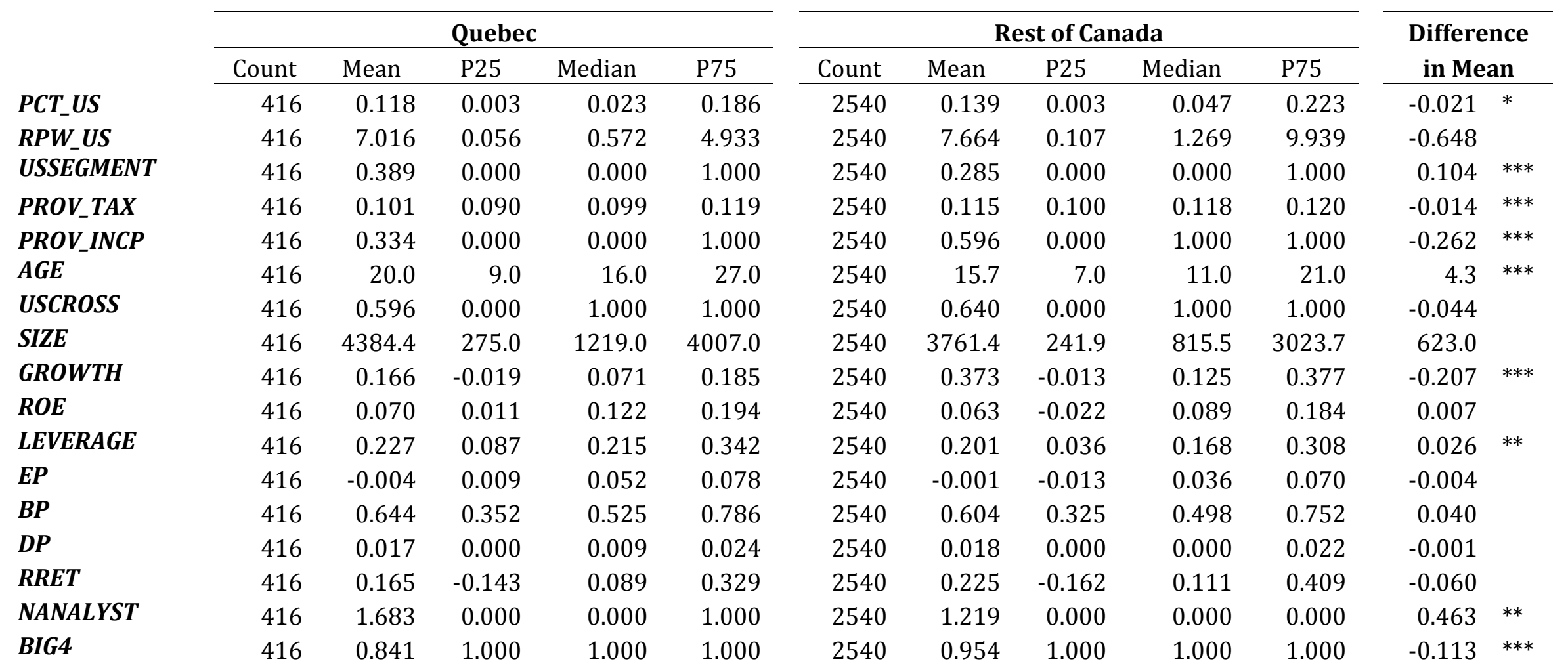

Note: variable definitions are given in Table 1. AGE, SIZE, and NANALYST are logged in the analysis but are reported here unlogged to aid in their interpretation. 
Table 3

Correlations Table: US Institutional holdings of Canadian firms (Full Sample)

Spearman Correlations above the diagonal and Pearson Correlations below the diagonal (p-values reported in italic)

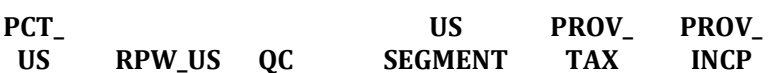

\begin{tabular}{|c|c|c|c|c|c|c|c|c|c|c|c|c|c|c|c|c|c|c|}
\hline & $\begin{array}{l}\text { PCT } \\
\text { US }\end{array}$ & RPW_US & QC & $\begin{array}{c}\text { US } \\
\text { SEGMENT }\end{array}$ & $\begin{array}{l}\text { PROV }_{-} \\
\text {TAX }\end{array}$ & $\begin{array}{l}\text { PROV }_{-} \\
\text {INCP }\end{array}$ & AGE & $\begin{array}{c}\text { US } \\
\text { CROSS }\end{array}$ & SIZE & GROWTH & ROE & LEV & EP & BP & DP & RRET & $\begin{array}{c}\mathbf{N} \\
\text { ANALYST }\end{array}$ & BIG4 \\
\hline \multirow[t]{2}{*}{ PCT_US } & 1 & 0.872 & -0.037 & 0.463 & 0.020 & -0.163 & 0.200 & 0.521 & 0.227 & 0.001 & -0.001 & 0.012 & -0.049 & -0.100 & -0.136 & -0.058 & 0.463 & 0.045 \\
\hline & 0.00 & 0.00 & 0.04 & 0.00 & 0.28 & 0.00 & 0.00 & 0.00 & 0.00 & 0.97 & 0.96 & 0.53 & 0.01 & 0.00 & 0.00 & 0.00 & 0.00 & 0.02 \\
\hline \multirow[t]{2}{*}{ RPW_US } & 0.415 & 1 & 0.009 & 0.406 & 0.007 & -0.252 & 0.356 & 0.488 & 0.589 & 0.007 & 0.169 & 0.081 & 0.118 & -0.164 & 0.100 & 0.027 & 0.419 & 0.114 \\
\hline & 0.00 & 0.00 & 0.64 & 0.00 & 0.71 & 0.00 & 0.00 & 0.00 & 0.00 & 0.73 & 0.00 & 0.00 & 0.00 & 0.00 & 0.00 & 0.15 & 0.00 & 0.00 \\
\hline \multirow[t]{2}{*}{ QC } & -0.041 & 0.014 & 1 & 0.079 & -0.386 & -0.184 & 0.121 & -0.032 & 0.056 & -0.090 & 0.045 & 0.072 & 0.069 & 0.029 & 0.059 & -0.015 & 0.026 & -0.163 \\
\hline & 0.03 & 0.46 & 0.00 & 0.00 & 0.00 & 0.00 & 0.00 & 0.09 & 0.00 & 0.00 & 0.01 & 0.00 & 0.00 & 0.11 & 0.00 & 0.43 & 0.16 & 0.00 \\
\hline \multirow[t]{2}{*}{ USSEGMENT } & 0.471 & 0.216 & 0.079 & 1 & 0.007 & -0.237 & 0.213 & 0.489 & 0.095 & -0.068 & -0.085 & 0.050 & -0.090 & -0.053 & -0.095 & -0.059 & 0.254 & 0.006 \\
\hline & 0.00 & 0.00 & 0.00 & 0.00 & 0.72 & 0.00 & 0.00 & 0.00 & 0.00 & 0.00 & 0.00 & 0.01 & 0.00 & 0.00 & 0.00 & 0.00 & 0.00 & 0.75 \\
\hline \multirow[t]{2}{*}{ PROV_TAX } & -0.034 & -0.059 & -0.306 & 0.028 & 1 & 0.052 & -0.100 & -0.052 & -0.157 & 0.074 & -0.035 & -0.054 & -0.042 & -0.069 & -0.104 & 0.042 & -0.142 & 0.031 \\
\hline & 0.06 & 0.00 & 0.00 & 0.13 & 0.00 & 0.00 & 0.00 & 0.00 & 0.00 & 0.00 & 0.06 & 0.00 & 0.02 & 0.00 & 0.00 & 0.02 & 0.00 & 0.10 \\
\hline \multirow[t]{2}{*}{ PROV_INCP } & -0.174 & -0.215 & -0.184 & -0.237 & 0.045 & 1 & -0.300 & -0.201 & -0.258 & 0.115 & -0.095 & -0.047 & -0.093 & 0.072 & -0.097 & 0.018 & -0.184 & -0.075 \\
\hline & 0.00 & 0.00 & 0.00 & 0.00 & 0.01 & 0.00 & 0.00 & 0.00 & 0.00 & 0.00 & 0.00 & 0.01 & 0.00 & 0.00 & 0.00 & 0.33 & 0.00 & 0.00 \\
\hline \multirow[t]{2}{*}{ AGE } & 0.198 & 0.327 & 0.120 & 0.215 & -0.101 & -0.301 & 1 & 0.266 & 0.498 & -0.230 & 0.186 & 0.173 & 0.226 & 0.021 & 0.290 & -0.039 & 0.159 & 0.142 \\
\hline & 0.00 & 0.00 & 0.00 & 0.00 & 0.00 & 0.00 & 0.00 & 0.00 & 0.00 & 0.00 & 0.00 & 0.00 & 0.00 & 0.24 & 0.00 & 0.04 & 0.00 & 0.00 \\
\hline \multirow[t]{2}{*}{ USCROSS } & 0.473 & 0.302 & -0.032 & 0.489 & -0.025 & -0.201 & 0.274 & 1 & 0.199 & -0.084 & -0.072 & 0.013 & -0.066 & -0.035 & -0.067 & -0.102 & 0.380 & 0.041 \\
\hline & 0.00 & 0.00 & 0.09 & 0.00 & 0.17 & 0.00 & 0.00 & 0.00 & 0.00 & 0.00 & 0.00 & 0.48 & 0.00 & 0.06 & 0.00 & 0.00 & 0.00 & 0.03 \\
\hline \multirow[t]{2}{*}{ SIZE } & 0.248 & 0.560 & 0.054 & 0.087 & -0.161 & -0.270 & 0.494 & 0.204 & 1 & -0.009 & 0.373 & 0.177 & 0.321 & -0.192 & 0.481 & 0.137 & 0.236 & 0.181 \\
\hline & 0.00 & 0.00 & 0.00 & 0.00 & 0.00 & 0.00 & 0.00 & 0.00 & 0.00 & 0.64 & 0.00 & 0.00 & 0.00 & 0.00 & 0.00 & 0.00 & 0.00 & 0.00 \\
\hline \multirow[t]{2}{*}{ GROWTH } & -0.045 & -0.066 & -0.069 & -0.071 & 0.072 & 0.096 & -0.240 & -0.080 & -0.091 & 1 & 0.204 & -0.045 & 0.123 & -0.169 & -0.135 & 0.156 & -0.056 & -0.020 \\
\hline & 0.01 & 0.00 & 0.00 & 0.00 & 0.00 & 0.00 & 0.00 & 0.00 & 0.00 & 0.00 & 0.00 & 0.01 & 0.00 & 0.00 & 0.00 & 0.00 & 0.00 & 0.27 \\
\hline \multirow[t]{2}{*}{ ROE } & -0.011 & 0.080 & 0.007 & -0.083 & -0.048 & -0.022 & 0.128 & -0.069 & 0.264 & 0.006 & 1 & 0.039 & 0.781 & -0.198 & 0.253 & 0.248 & 0.016 & 0.044 \\
\hline & 0.56 & 0.00 & 0.70 & 0.00 & 0.01 & 0.24 & 0.00 & 0.00 & 0.00 & 0.76 & 0.00 & 0.03 & 0.00 & 0.00 & 0.00 & 0.00 & 0.40 & 0.02 \\
\hline \multirow[t]{2}{*}{ LEVERAGE } & 0.048 & 0.018 & 0.050 & 0.033 & -0.033 & -0.019 & 0.118 & 0.000 & 0.100 & -0.089 & -0.011 & 1 & 0.068 & 0.053 & 0.332 & -0.040 & -0.019 & -0.019 \\
\hline & 0.01 & 0.33 & 0.01 & 0.08 & 0.08 & 0.30 & 0.00 & 1.00 & 0.00 & 0.00 & 0.56 & 0.00 & 0.00 & 0.00 & 0.00 & 0.03 & 0.29 & 0.30 \\
\hline \multirow[t]{2}{*}{ EP } & -0.020 & 0.087 & -0.007 & -0.078 & -0.035 & -0.011 & 0.108 & -0.100 & 0.301 & 0.029 & 0.531 & -0.055 & 1 & 0.115 & 0.325 & 0.150 & 0.000 & 0.012 \\
\hline & 0.27 & 0.00 & 0.71 & 0.00 & 0.06 & 0.54 & 0.00 & 0.00 & 0.00 & 0.12 & 0.00 & 0.00 & 0.00 & 0.00 & 0.00 & 0.00 & 0.98 & 0.52 \\
\hline \multirow[t]{2}{*}{ BP } & -0.089 & -0.114 & 0.031 & -0.031 & -0.029 & 0.054 & 0.002 & -0.019 & -0.264 & -0.084 & -0.069 & 0.004 & -0.178 & 1 & 0.080 & -0.335 & -0.071 & -0.082 \\
\hline & 0.00 & 0.00 & 0.10 & 0.09 & 0.11 & 0.00 & 0.92 & 0.31 & 0.00 & 0.00 & 0.00 & 0.83 & 0.00 & 0.00 & 0.00 & 0.00 & 0.00 & 0.00 \\
\hline \multirow[t]{2}{*}{ DP } & -0.185 & -0.020 & -0.008 & -0.134 & -0.029 & 0.050 & -0.002 & -0.118 & 0.130 & -0.081 & 0.089 & 0.283 & 0.088 & 0.051 & 1 & -0.008 & 0.012 & 0.069 \\
\hline & 0.00 & 0.27 & 0.65 & 0.00 & 0.11 & 0.01 & 0.92 & 0.00 & 0.00 & 0.00 & 0.00 & 0.00 & 0.00 & 0.01 & 0.00 & 0.67 & 0.52 & 0.00 \\
\hline \multirow[t]{2}{*}{ RRET } & -0.057 & -0.027 & -0.032 & -0.057 & 0.036 & 0.047 & -0.100 & -0.098 & 0.030 & 0.105 & 0.116 & -0.093 & 0.202 & -0.282 & -0.103 & 1 & -0.052 & -0.001 \\
\hline & 0.00 & 0.15 & 0.09 & 0.00 & 0.05 & 0.01 & 0.00 & 0.00 & 0.11 & 0.00 & 0.00 & 0.00 & 0.00 & 0.00 & 0.00 & 0.00 & 0.00 & 0.96 \\
\hline \multirow[t]{2}{*}{ NANALYST } & 0.466 & 0.219 & 0.040 & 0.268 & -0.151 & -0.192 & 0.162 & 0.361 & 0.257 & -0.047 & 0.000 & -0.042 & 0.010 & -0.071 & -0.061 & -0.052 & 1 & 0.054 \\
\hline & 0.00 & 0.00 & 0.03 & 0.00 & 0.00 & 0.00 & 0.00 & 0.00 & 0.00 & 0.01 & 0.99 & 0.02 & 0.57 & 0.00 & 0.00 & 0.00 & 0.00 & 0.00 \\
\hline \multirow[t]{2}{*}{ BIG4 } & 0.036 & 0.092 & -0.163 & 0.006 & 0.003 & -0.075 & 0.141 & 0.041 & 0.185 & -0.014 & 0.004 & -0.030 & 0.027 & -0.088 & 0.021 & -0.007 & 0.050 & 1 \\
\hline & 0.05 & 0.00 & 0.00 & 0.75 & 0.86 & 0.00 & 0.00 & 0.03 & 0.00 & 0.46 & 0.83 & 0.11 & 0.14 & 0.00 & 0.25 & 0.71 & 0.01 & 0.00 \\
\hline
\end{tabular}


Table 4

\section{Regression of U.S. institutional holdings on QC dummy and control variables}

\begin{tabular}{|c|c|c|c|c|c|}
\hline \multirow{4}{*}{ MODEL } & \multirow{5}{*}{$\begin{array}{c}\text { Prediction } \\
\text { Selection, Final }\end{array}$} & \multirow{2}{*}{\multicolumn{2}{|c|}{$\begin{array}{c}\text { Zero-Inflated Beta } \\
\text { Full sample }\end{array}$}} & \multicolumn{2}{|c|}{ Heckman two stage } \\
\hline & & & & \multicolumn{2}{|c|}{ Full sample } \\
\hline & & (1) & (2) & (3) & (4) \\
\hline & & Selection & Final & Selection & Final \\
\hline VARIABLES & & PCT_US & PCT_US & RPW_US & RPW_US \\
\hline QC &,+- & $\begin{array}{c}\mathbf{0 . 2 7 7 * * *} \\
(2.745)\end{array}$ & $\begin{array}{c}\mathbf{- 0 . 4 4 5 * * *} \\
(-6.546)\end{array}$ & $\begin{array}{c}\mathbf{0 . 1 6 4}^{* * *} \\
(2.767)\end{array}$ & $\begin{array}{c}\mathbf{- 2 . 1 7 4} \mathbf{1}^{* * *} \\
(-2.979)\end{array}$ \\
\hline S\&PTSX & - & $\begin{array}{l}-0.197^{* *} \\
(-2.208)\end{array}$ & & $\begin{array}{l}-0.125^{* *} \\
(-2.417)\end{array}$ & \\
\hline PROV_TAX &,+- & $\begin{array}{c}1.227 \\
(0.546)\end{array}$ & $\begin{array}{l}-3.983^{* * *} \\
(-2.973)\end{array}$ & $\begin{array}{c}0.980 \\
(0.754)\end{array}$ & $\begin{array}{c}1.201 \\
(0.077)\end{array}$ \\
\hline PROV_INCP &,+- & $\begin{array}{c}-0.080 \\
(-1.079)\end{array}$ & $\begin{array}{c}0.150^{* * *} \\
(2.892)\end{array}$ & $\begin{array}{l}-0.040 \\
(-0.941)\end{array}$ & $\begin{array}{c}0.328 \\
(0.680)\end{array}$ \\
\hline USCROSS &,-+ & $\begin{array}{l}-1.140^{* * *} \\
(-10.329)\end{array}$ & $\begin{array}{l}0.747^{* * *} \\
(10.991)\end{array}$ & $\begin{array}{l}-0.679^{* * *} \\
(-10.695)\end{array}$ & $\begin{array}{c}0.118 \\
(0.120)\end{array}$ \\
\hline USSEGMENT &,-+ & $\begin{array}{l}-0.729^{* * *} \\
(-5.528)\end{array}$ & $\begin{array}{l}0.485^{* * *} \\
(7.182)\end{array}$ & $\begin{array}{l}-0.424^{* * *} \\
(-5.610)\end{array}$ & $\begin{array}{c}0.474 \\
(0.487)\end{array}$ \\
\hline SIZE &,-+ & $\begin{array}{l}-0.493^{* * *} \\
(-14.326)\end{array}$ & $\begin{array}{l}0.182^{* * *} \\
(10.440)\end{array}$ & $\begin{array}{l}-0.280^{* * *} \\
(-14.712)\end{array}$ & $\begin{array}{l}-0.995^{* *} \\
(-2.136)\end{array}$ \\
\hline GROWTH &,-+ & $\begin{array}{c}-0.026 \\
(-0.804)\end{array}$ & $\begin{array}{c}0.002 \\
(0.146)\end{array}$ & $\begin{array}{c}-0.014 \\
(-0.758)\end{array}$ & $\begin{array}{c}-0.090 \\
(-0.490)\end{array}$ \\
\hline ROE &,-+ & $\begin{array}{c}0.061 \\
(0.618)\end{array}$ & $\begin{array}{c}0.067 \\
(0.903)\end{array}$ & $\begin{array}{c}0.041 \\
(0.723)\end{array}$ & $\begin{array}{c}0.642 \\
(0.935)\end{array}$ \\
\hline AGE & $?$ & $\begin{array}{c}-0.157^{* * *} \\
(-2.636)\end{array}$ & $\begin{array}{c}-0.010 \\
(-0.238)\end{array}$ & $\begin{array}{l}-0.093^{* * *} \\
(-2.783)\end{array}$ & $\begin{array}{c}-0.097 \\
(-0.220)\end{array}$ \\
\hline LEVERAGE & $?$ & $\begin{array}{c}-0.180 \\
(-0.851)\end{array}$ & $\begin{array}{l}0.422^{* * *} \\
(2.686)\end{array}$ & $\begin{array}{c}-0.066 \\
(-0.553)\end{array}$ & $\begin{array}{l}8.640^{* * *} \\
(4.540)\end{array}$ \\
\hline EP & $?$ & $\begin{array}{c}0.680^{* * *} \\
(4.167)\end{array}$ & $\begin{array}{c}0.100 \\
(0.738)\end{array}$ & $\begin{array}{c}0.388^{* * *} \\
(4.195)\end{array}$ & $\begin{array}{l}4.312^{* * *} \\
(2.747)\end{array}$ \\
\hline BP & $?$ & $\begin{array}{l}0.133^{*} \\
(1.777)\end{array}$ & $\begin{array}{c}0.012 \\
(0.222)\end{array}$ & $\begin{array}{l}0.076^{*} \\
(1.776)\end{array}$ & $\begin{array}{c}2.052^{* * *} \\
(2.984)\end{array}$ \\
\hline DP & $?$ & $\begin{array}{l}9.785^{* * *} \\
(7.302)\end{array}$ & $\begin{array}{c}-5.058^{* * *} \\
(-7.254)\end{array}$ & $\begin{array}{c}5.023^{* * *} \\
(7.317)\end{array}$ & $\begin{array}{c}1.093 \\
(0.163)\end{array}$ \\
\hline RRET & $?$ & $\begin{array}{c}0.058 \\
(1.006)\end{array}$ & $\begin{array}{c}-0.147^{* * *} \\
(-4.255)\end{array}$ & $\begin{array}{c}0.028 \\
(0.864)\end{array}$ & $\begin{array}{c}-0.319 \\
(-0.959)\end{array}$ \\
\hline NANALYST &,-+ & $\begin{array}{c}-1.972^{* * *} \\
(-8.307)\end{array}$ & $\begin{array}{l}0.517^{* * *} \\
(12.931)\end{array}$ & $\begin{array}{c}-1.005^{* * *} \\
(-9.170)\end{array}$ & $\begin{array}{c}-8.339 * * * \\
(-4.942)\end{array}$ \\
\hline BIG4 &,-+ & $\begin{array}{c}0.100 \\
(0.795)\end{array}$ & $\begin{array}{l}-0.188^{* *} \\
(-2.425)\end{array}$ & $\begin{array}{c}0.058 \\
(0.833)\end{array}$ & $\begin{array}{l}-0.220 \\
(-0.225)\end{array}$ \\
\hline INVERSE_MILL & $?$ & & & & $\begin{array}{c}11.673^{* * *} \\
(6.411)\end{array}$ \\
\hline CONSTANT & $?$ & $\begin{array}{l}5.518^{* * *} \\
(12.806)\end{array}$ & $\begin{array}{l}-4.458^{* * *} \\
(-15.836)\end{array}$ & $\begin{array}{l}3.180^{* * *} \\
(13.558)\end{array}$ & $\begin{array}{c}3.695 \\
(0.969)\end{array}$ \\
\hline Industry FE & & YES & YES & YES & YES \\
\hline Year FE & & YES & YES & YES & YES \\
\hline R-squared & & & & & 0.3715 \\
\hline ln_phi & & $\begin{array}{l}1.739^{* * *} \\
(41.913)\end{array}$ & & & \\
\hline Observations & & 8,089 & 8,089 & 8,089 & 2,956 \\
\hline
\end{tabular}

Robust t-statistics (z-statistics) in parentheses for ZOIB model (Heckman model)

${ }^{* * *} \mathrm{p}<0.01,{ }^{* *} \mathrm{p}<0.05,{ }^{*} \mathrm{p}<0.1$. Errors are clustered by industry and year 
Table 5

Regression of U.S. institutional holdings on QC dummy and control variables (alternate specifications and robustness)

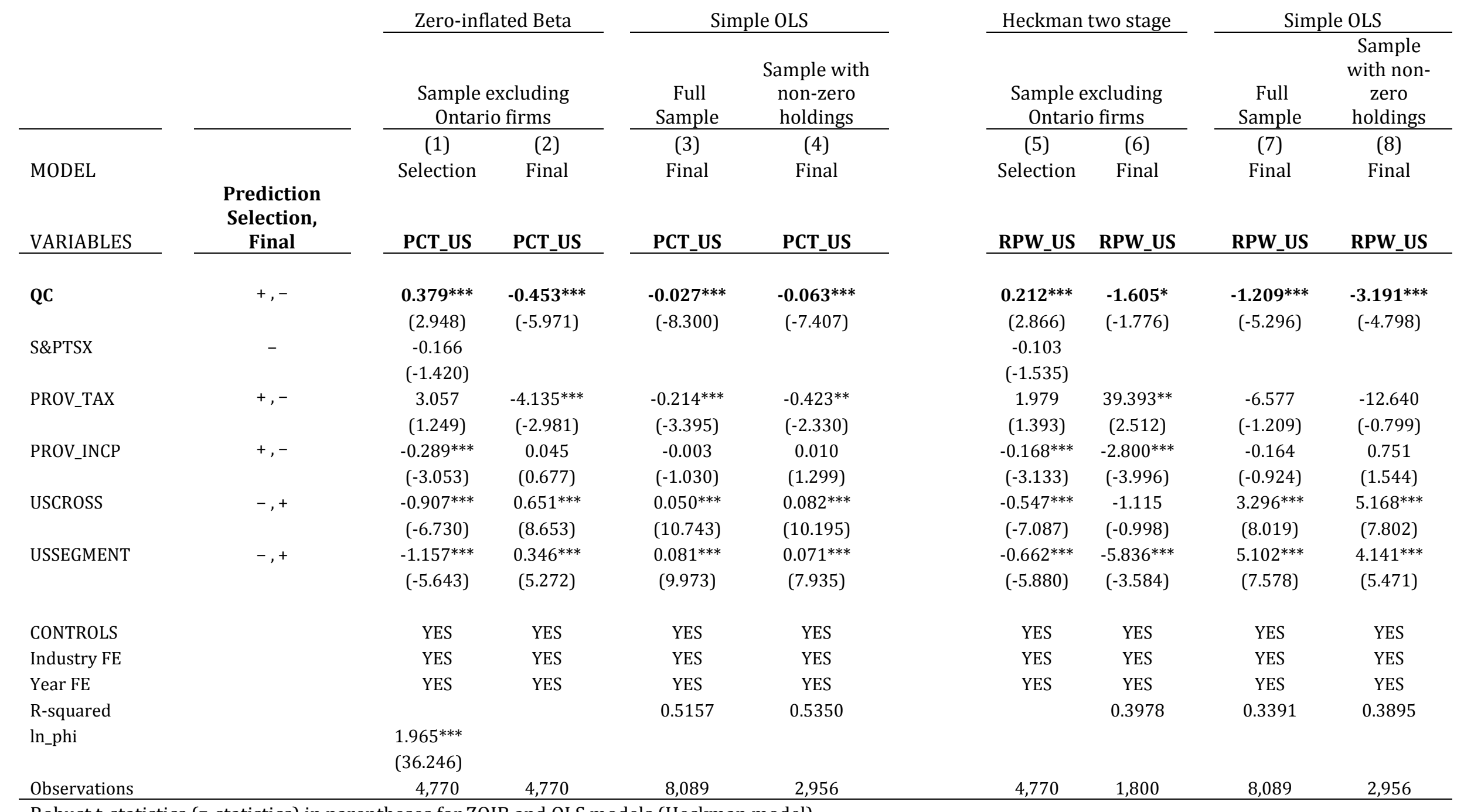

Robust t-statistics (z-statistics) in parentheses for ZOIB and OLS models (Heckman model)

*** $\mathrm{p}<0.01,{ }^{* *} \mathrm{p}<0.05,{ }^{*} \mathrm{p}<0.1$. Errors are clustered by industry and year 
Table 6

Panel A. US investor bias investigation: regression using matched pair sample

Sample Consists of all the Quebec firm-years with non-zero US holdings, and their size matched non-zero-US-holding firms from Rest of Canada

\begin{tabular}{|c|c|c|c|}
\hline VARIABLES & Prediction & $\begin{array}{c}\text { Beta Model } \\
(1) \\
\text { PCT_US }\end{array}$ & $\begin{array}{c}\text { OLS } \\
(2) \\
\text { RPW_US }\end{array}$ \\
\hline QC & - & $\begin{array}{c}-\mathbf{0 . 5 9 6} * * * \\
(-5.034)\end{array}$ & $\begin{array}{c}-3.879 * * * \\
(-3.273)\end{array}$ \\
\hline PROV_TAX & - & $\begin{array}{l}-7.839^{* *} \\
(-2.404)\end{array}$ & $\begin{array}{l}-13.594 \\
(-0.399)\end{array}$ \\
\hline PROV_INCP & - & $\begin{array}{c}0.357^{* * *} \\
(3.709)\end{array}$ & $\begin{array}{l}2.905^{* *} \\
(2.224)\end{array}$ \\
\hline USCROSS & + & $\begin{array}{c}0.817^{* * *} \\
(6.943)\end{array}$ & $\begin{array}{c}5.077^{* * *} \\
(3.417)\end{array}$ \\
\hline USSEGMENT & + & $\begin{array}{c}0.508^{* * *} \\
(4.168)\end{array}$ & $\begin{array}{c}4.707^{* * *} \\
(3.104)\end{array}$ \\
\hline $\begin{array}{l}\text { CONTROLS } \\
\text { Industry FE } \\
\text { Year FE }\end{array}$ & & $\begin{array}{l}\text { YES } \\
\text { YES } \\
\text { YES }\end{array}$ & $\begin{array}{l}\text { YES } \\
\text { YES } \\
\text { YES }\end{array}$ \\
\hline $\begin{array}{l}\text { R-squared } \\
\text { ln_phi }\end{array}$ & & $\begin{array}{l}1.972^{* * *} \\
(25.512)\end{array}$ & 0.4637 \\
\hline Observations & & 832 & 832 \\
\hline
\end{tabular}


Table 7

Descriptive Statistics: US Institutional holdings of Quebec firms (Only firm-years with non-zero holdings)

\begin{tabular}{|c|c|c|c|c|c|c|c|c|c|c|c|c|}
\hline \multirow{4}{*}{ FRENCHNESS } & \multirow{2}{*}{\multicolumn{5}{|c|}{ Above Median FRENCHNESS }} & \multirow{2}{*}{\multicolumn{5}{|c|}{ Below Median FRENCHNESS }} & \multirow{3}{*}{\multicolumn{2}{|c|}{$\begin{array}{c}\text { Difference } \\
\text { in Mean }\end{array}$}} \\
\hline & & & & & & & & & & & & \\
\hline & \multirow{2}{*}{$\begin{array}{r}\text { Count } \\
193\end{array}$} & \multirow{2}{*}{$\begin{array}{l}\text { Mean } \\
0.430\end{array}$} & \multirow{2}{*}{$\begin{array}{l}\mathrm{P} 25 \\
0.323\end{array}$} & \multirow{2}{*}{$\begin{array}{r}\text { Median } \\
0.400\end{array}$} & \multirow{2}{*}{$\frac{\mathrm{P} 75}{0.521}$} & \multirow{2}{*}{$\begin{array}{r}\text { Count } \\
193\end{array}$} & \multirow{2}{*}{$\begin{array}{c}\text { Mean } \\
0.123\end{array}$} & \multirow{2}{*}{$\begin{array}{l}\mathrm{P} 25 \\
0.054\end{array}$} & \multirow{2}{*}{$\begin{array}{r}\text { Median } \\
0.122\end{array}$} & \multirow{2}{*}{$\frac{\mathrm{P} 75}{0.192}$} & & \\
\hline & & & & & & & & & & & 0.307 & $* * *$ \\
\hline$W E B$ & 193 & 4.535 & 2.708 & 4.595 & 5.872 & 193 & 4.788 & 3.466 & 4.477 & 5.908 & -0.253 & \\
\hline FPCT_US & 193 & 0.074 & 0.002 & 0.010 & 0.088 & 193 & 0.134 & 0.003 & 0.037 & 0.213 & -0.059 & $* * *$ \\
\hline$R P W_{-} U S$ & 193 & 5.471 & 0.034 & 0.270 & 2.267 & 193 & 6.432 & 0.081 & 0.727 & 3.453 & -0.961 & \\
\hline USSEGMENT & 193 & 1.762 & 0.000 & 0.000 & 2.000 & 193 & 1.984 & 0.000 & 0.000 & 3.000 & -0.223 & \\
\hline PROV_TAX & 193 & 0.102 & 0.090 & 0.099 & 0.119 & 193 & 0.102 & 0.090 & 0.099 & 0.119 & 0.000 & \\
\hline PROV_INCP & 193 & 0.409 & 0.000 & 0.000 & 1.000 & 193 & 0.290 & 0.000 & 0.000 & 1.000 & 0.119 & $*$ \\
\hline$A G E$ & 193 & 19.8 & 7.0 & 17.0 & 26.0 & 193 & 21.4 & 11.0 & 17.0 & 29.0 & -1.5 & \\
\hline USCROSS & 193 & 0.461 & 0.000 & 0.000 & 1.000 & 193 & 0.684 & 0.000 & 1.000 & 1.000 & -0.223 & $* * *$ \\
\hline SIZE & 193 & 3893.7 & 256.9 & 1199.5 & 5412.7 & 193 & 5328.1 & 337.4 & 1304.9 & 3854.8 & -1434.4 & \\
\hline GROWTH & 193 & 0.242 & -0.018 & 0.081 & 0.195 & 193 & 0.100 & -0.005 & 0.079 & 0.173 & 0.142 & $*$ \\
\hline$R O E$ & 193 & 0.059 & -0.017 & 0.113 & 0.188 & 193 & 0.119 & 0.057 & 0.138 & 0.208 & -0.060 & \\
\hline LEVERAGE & 193 & 0.217 & 0.058 & 0.207 & 0.315 & 193 & 0.227 & 0.116 & 0.229 & 0.341 & -0.010 & \\
\hline$E P$ & 193 & 0.002 & -0.012 & 0.051 & 0.078 & 193 & 0.018 & 0.031 & 0.056 & 0.076 & -0.015 & \\
\hline$B P$ & 193 & 0.586 & 0.351 & 0.519 & 0.699 & 193 & 0.647 & 0.348 & 0.482 & 0.771 & -0.061 & \\
\hline$D P$ & 193 & 0.017 & 0.000 & 0.012 & 0.025 & 193 & 0.018 & 0.000 & 0.009 & 0.024 & -0.001 & \\
\hline RRET & 193 & 0.187 & -0.131 & 0.098 & 0.331 & 193 & 0.169 & -0.139 & 0.116 & 0.353 & 0.018 & \\
\hline NANALYST & 193 & 0.777 & 0.000 & 0.000 & 0.000 & 193 & 2.363 & 0.000 & 0.000 & 3.000 & -1.585 & $* * *$ \\
\hline BIG4 & 193 & 0.865 & 1.000 & 1.000 & 1.000 & 193 & 0.808 & 1.000 & 1.000 & 1.000 & 0.057 & \\
\hline
\end{tabular}

Note: variable definitions are given in Table 1. AGE, SIZE, and NANALYST are logged in the analysis but are reported here unlogged to aid in their interpretation. There are 416 Quebec firm-years with non-zero holdings, but only 386 of them have an Internet presence in a specific year that can be identified, resulting in two samples of 193 firm-years. 
Table 8

\section{Regression of U.S. institutional holdings on FRENCHNESS and control variables}

\begin{tabular}{|c|c|c|c|}
\hline & & Beta Model & OLS \\
\hline VARIABLES & Prediction & $\begin{array}{c}\text { Only Non-Zero } \\
\text { Holdings } \\
(1) \\
\text { PCT_US }\end{array}$ & $\begin{array}{c}\text { Only Non- } \\
\text { Zero Holdings } \\
\text { (2) } \\
\text { RPW US }\end{array}$ \\
\hline FRENCHNESS & - & $\begin{array}{c}-\mathbf{0 . 6 7 1} * * \\
(-2.567)\end{array}$ & $\begin{array}{l}-7.911 * \\
(-1.732)\end{array}$ \\
\hline WEB & $?$ & $\begin{array}{l}0.0217 \\
(0.289)\end{array}$ & $\begin{array}{c}0.112 \\
(0.181)\end{array}$ \\
\hline PROV_INCP & - & $\begin{array}{c}-0.0109 \\
(-0.0618)\end{array}$ & $\begin{array}{c}-1.240 \\
(-0.850)\end{array}$ \\
\hline USCROSS & + & $\begin{array}{c}0.863^{* * *} \\
(5.925)\end{array}$ & $\begin{array}{c}6.205^{* * *} \\
(2.989)\end{array}$ \\
\hline USSEGMENT & + & $\begin{array}{c}0.0698 \\
(0.365)\end{array}$ & $\begin{array}{c}-2.000 \\
(-0.622)\end{array}$ \\
\hline CONTROLS & & YES & YES \\
\hline Industry FE & & YES & YES \\
\hline Year FE & & YES & YES \\
\hline R-squared & & & 0.528 \\
\hline ln_phi & & $\begin{array}{c}2.947^{* * *} \\
(26.12)\end{array}$ & \\
\hline Observations & 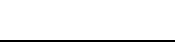 & 386 & 386 \\
\hline
\end{tabular}

There are 416 Quebec firm-year observations, but only 386 of them have the required online presence in a year. See Appendix 2 for details. 
Table 9

Descriptive Statistics: European institutional holdings of Canadian firms

Panel A: UK investor holdings of Canadian firms (only firm-years with non-zero holdings)

\begin{tabular}{lrrrrr}
\cline { 2 - 6 } & \multicolumn{5}{c}{ Quebec } \\
\cline { 2 - 6 } & Count & \multicolumn{1}{c}{ Mean } & \multicolumn{1}{c}{ P25 } & Median & \multicolumn{1}{c}{ P75 } \\
\cline { 2 - 6 } PCT_UK(\%) & 459 & $0.67 \%$ & $0.05 \%$ & $0.18 \%$ & $0.58 \%$ \\
RPW_UK & 459 & 11.372 & 0.226 & 1.349 & 5.393 \\
EUSEGMENT & 459 & 0.192 & 0.000 & 0.000 & 0.000 \\
EUCROSS & 459 & 0.414 & 0.000 & 0.000 & 1.000 \\
PROV_TAX & 459 & 0.103 & 0.090 & 0.099 & 0.119 \\
PROV_INCP & 459 & 0.351 & 0.000 & 0.000 & 1.000
\end{tabular}

\begin{tabular}{rrrrr}
\hline \multicolumn{5}{c}{ Rest of Canada } \\
\hline Count & \multicolumn{1}{c}{ Mean } & \multicolumn{1}{c}{ P25 } & \multicolumn{1}{c}{ Median } & \multicolumn{1}{c}{ P75 } \\
\hline 2319 & $1.21 \%$ & $0.05 \%$ & $0.23 \%$ & $1.17 \%$ \\
2319 & 25.335 & 0.455 & 3.226 & 19.079 \\
2319 & 0.134 & 0.000 & 0.000 & 0.000 \\
2319 & 0.559 & 0.000 & 1.000 & 1.000 \\
2319 & 0.114 & 0.100 & 0.115 & 0.120 \\
2319 & 0.564 & 0.000 & 1.000 & 1.000
\end{tabular}

\begin{tabular}{rr}
\hline \multicolumn{2}{c}{ Difference } \\
in Mean \\
\hline-0.005 & $* * *$ \\
-13.963 & $* * *$ \\
0.058 & $* * *$ \\
-0.145 & $* * *$ \\
-0.011 & $* * *$ \\
-0.213 & $* * *$
\end{tabular}

Panel B: French investor holdings of Canadian firms (only firm-years with non-zero holdings)

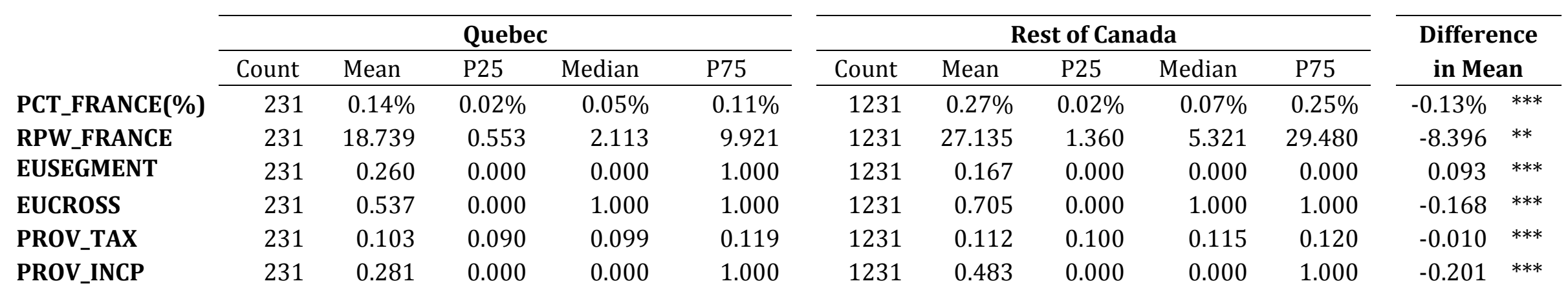


Table 10

Regression of UK and French institutional holdings on Quebec dummy and control variables

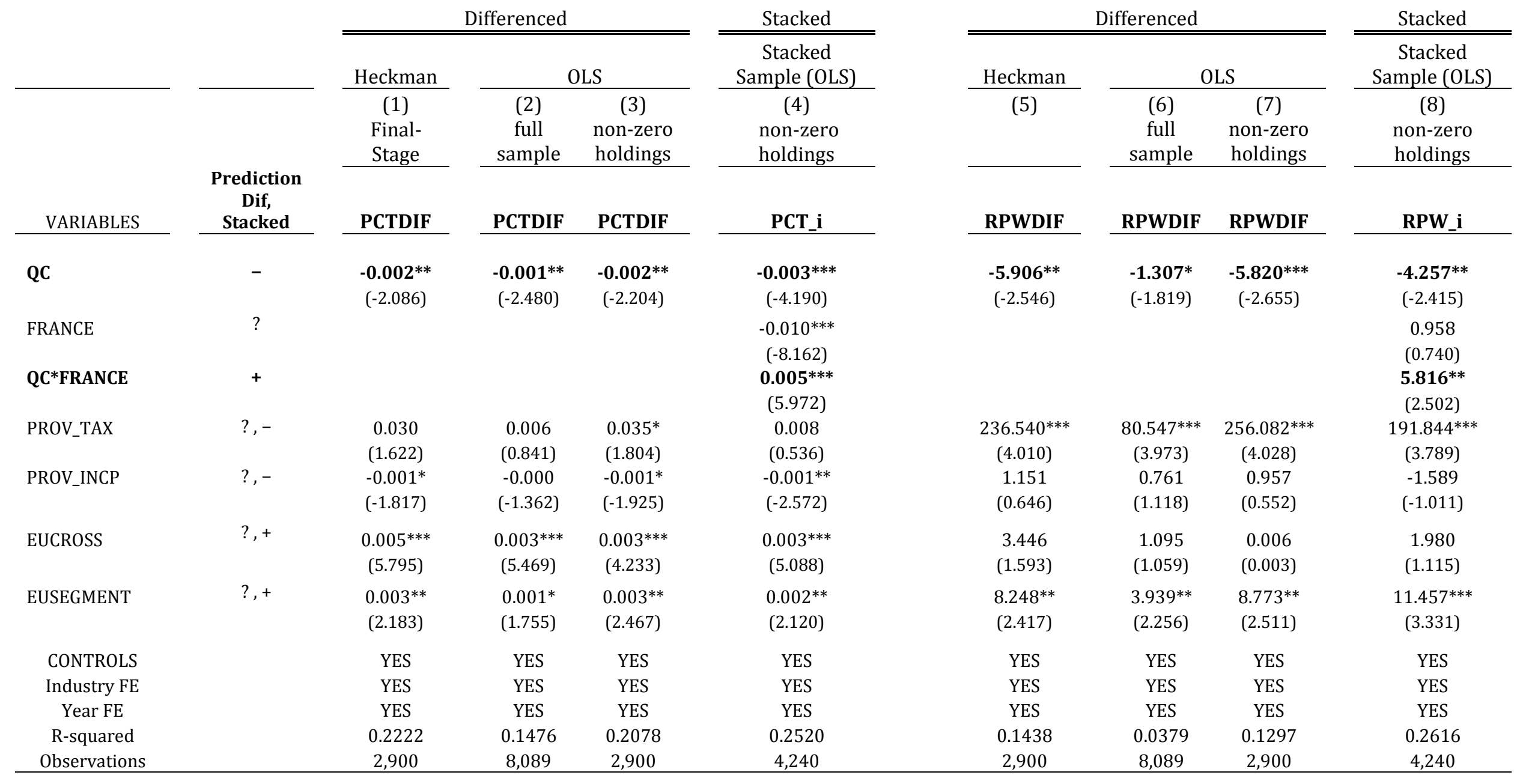

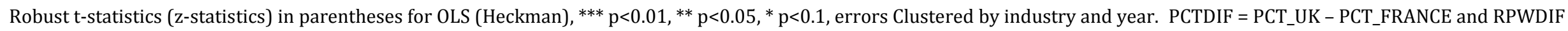

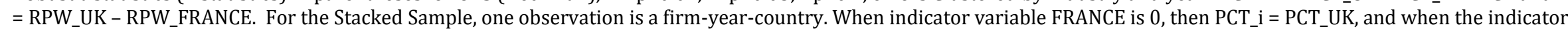
variable FRANCE is 1, then PCT_ $\mathrm{i}=$ PCT_FRANCE. RPW_ $\mathrm{i}$ is constructed in the same way. 